\title{
Critical appraisal of denosumab in the treatment and prevention of postmenopausal osteoporosis and bone loss in patients undergoing hormone ablation
}

\author{
This article was published in the following Dove Press journal: \\ Orthopedic Research and Reviews \\ 24 September 2010 \\ Number of times this article has been viewed
}

\author{
David L Kendler' \\ Kenneth Shawn Davison ${ }^{2}$ \\ 'Prohealth Clinical Research, \\ University of British Columbia, \\ Vancouver, British Columbia, Canada; \\ ${ }^{2}$ Department of Medicine, Division of \\ Immunology and Rheumatology, Laval \\ University, Quebec, Canada
}

\begin{abstract}
Antiresorptive therapies are the mainstay for treating patients with excessively high rates of bone resorption. The receptor activator of nuclear factor- $\kappa \mathrm{B}$ (RANK) ligand (RANKL), secreted by osteoblasts, binds to the RANK receptor on the surface of preosteoclasts and osteoclasts to elicit osteoclast formation, survival, and activity. Osteoprotegerin, also secreted by the osteoblast, acts as a decoy RANK receptor reducing RANKL binding to RANK and reducing bone resorption. Denosumab, a fully human monoclonal antibody, has a high affinity and specificity for RANKL. Denosumab rapidly decreases bone resorption and increases bone mineral density (BMD) at the lumbar spine, total hip, femoral neck, and one-third radius sites. In head-to-head trials, denosumab increased BMD and decreased bone resorption to a significantly greater degree than alendronate. In postmenopausal osteoporotic women, denosumab decreased the risk of vertebral fracture (68\%), nonvertebral fracture (20\%), and hip fracture (40\%) over 36 months, compared to placebo. In patients with iatrogenic hypogonadism, denosumab rapidly decreased markers of bone resorption and increased BMD. In men treated with GnRH agonist for prostate cancer, treatment with denosumab led to a $62 \%$ decreased risk of new vertebral fracture over 3 years, as compared to placebo. In all trials completed to date, comparable adverse events have been observed in both denosumab and placebo or treatment groups.
\end{abstract}

Keywords: medication adherence, fracture, bone mineral density, bone turnover markers

\section{Introduction}

\section{Burden of illness in postmenopausal osteoporosis}

Osteoporosis is a disease characterized by decreased bone mass and microarchitectural deterioration of bone, resulting in reduced bone strength and a predisposition to fragility fracture. ${ }^{1}$ Fragility fractures are associated with substantial decreases in both quality ${ }^{2,3}$ and length of life. ${ }^{4}$ Due to our aging demographic and increasing lifespan, the cost of treating osteoporosis and fragility fractures is growing. ${ }^{5}$

Osteoporosis is asymptomatic prior to fracture, making its management challenging, since many at risk do not believe they need intervention and many who initiate treatment find the medications inconvenient or associated with unwanted side effects. ${ }^{6}$

The goal of osteoporosis therapy is the prevention of fragility fractures. The most effective therapies need to be efficacious in decreasing fracture risk and easy to adhere to.

\section{Burden of illness in iatrogenic hypogonadism}

The recurrence of sex-hormone-sensitive cancers, such as estrogen-receptor positive breast cancer in women or prostate cancer in men, can be reduced by eliminating tumor
Correspondence: David L Kendler Prohealth Clinical Research, 600-1285 West Broadway, Vancouver, $\mathrm{V} 6 \mathrm{H} 3 \times 8$, Canada

$\mathrm{Tel}+\mid$ 604-263-366|

Fax +I 604-263-374

Email kendler@ca.inter.net 
stimulation through reductions in circulating sex steroids. This can be accomplished either surgically (gonadectomy) or through medications. Testosterone conversion to estradiol by peripheral aromatase can be inhibited by aromatase-inhibitor medications, and gonadatropin-releasing hormone agonists can be used in men or women to centrally suppress gonadal steroid production.

Aromatase-inhibitor medications are used with increasing frequency and longer duration in patients with estrogen-receptor positive breast cancer, improving disease-free survival and with significantly fewer life-threatening adverse events (AEs) as compared to tamoxifene therapy. ${ }^{7-11}$ Aromatase-inhibitor medications reduce the conversion of androgens to estradiol in peripheral tissues, reducing circulating estrogen levels. Since even low levels of circulating estradiol can lead to reduced bone resorption, long-term aromatase-inhibitor therapy leads to accelerated bone loss and increased risk for fracture..$^{8-10,12-19}$

Androgen-deprivation therapy (ADT) with intermittent gonadatropin-releasing hormone agonists is an increasingly popular therapy for men with metastatic and nonmetastatic high-risk prostate cancer. Other options of orchidectomy or inhibitors of testosterone biosynthesis also lead to reductions in circulating testosterone and estradiol (produced by aromatization of testosterone peripherally). ${ }^{20-22}$ With reduced circulating testosterone, whether the result of orchidectomy or medical therapy, there are substantial losses in bone mass and increases in fracture risk. ${ }^{23-27}$

Bone metastatic disease in prostate cancer or breast cancer is particularly harmful to the bone. Tumor deposit in bone liberates cytokines that activate osteoclasts to resorb bone (through the receptor activator of nuclear factor- $\kappa \mathrm{B}$ [RANK] - RANK ligand [RANKL] signaling pathway). The products of resorbed bone likely include cytokines and growth factors that, in turn, stimulate tumor proliferation. This vicious cycle can be disrupted by potent antiresorptive therapies, which either interfere with the ability of the tumor to activate osteoclasts (denosumab) or which cause mature osteoclasts to apoptose (bisphosphonates). If unchecked, marked local bone loss and mechanically insufficient bone accretion at the site of the tumor may lead to pathologic fracture at such sites. ${ }^{28,29}$ Patients with hormone-sensitive cancer metastatic to bone have the risk of excess bone resorption, skeletal-related AEs, disease progression, and death. ${ }^{30}$

\section{Bone protective therapy in iatrogenic hypogonadism}

Iatrogenic hypogonadism improves cancer disease-free survival in patients with hormone-sensitive tumors.
The attendant increases in bone resorption are the most rapid in the initial year of therapy. ${ }^{31}$ There is a direct relationship between fracture risk and the time a patient remains on ADT, with patients on therapy for a longer duration being at greatest risk for fragility fracture. ${ }^{23,24,32-34}$ Similarly, aromataseinhibitor treatment for breast cancer leads to rapid bone loss and increased fragility fracture risk, ${ }^{35,36}$ with fragility fracture risk increasing with increasing duration of therapy. ${ }^{8-10}$

Therefore, bone-sparing therapies are best initiated concurrent with therapies that induce hypogonadism and continued for the duration of therapy. Later introduction of osteoporosis therapies remains effective, but in such cases since architectural deterioration has already occurred, optimal prevention of fragility fracture cannot be easily achieved with antiresorptive therapies. If bone protective therapy is initiated concurrent with iatrogenic hypogonadism, maintenance or increases of bone mass may be achieved with effective fracture risk reduction. ${ }^{37,38}$

\section{Fracture risk assessment}

Epidemiologically, bone mineral density (BMD) assessed by dual-energy x-ray absorptiometry (DXA) at the hip, spine, or radius is used to define osteoporosis in a postmenopausal woman or man older than 50 years. ${ }^{39}$ However, while the risk for fragility fracture is greatest for those individuals with a $\mathrm{BMD}$ in the range of osteoporosis (BMD T-score $\leq-2.5$ ), a greater absolute number of fractures occur in individuals with low, but not osteoporotic, BMD (BMD T-score from -1.0 to -2.5$).{ }^{40,41}$ Fracture risk changes with age, independent of $\mathrm{BMD},{ }^{42}$ and prior personal history of fragility fracture is one of the most powerful predictors of fragility fracture, regardless of BMD. ${ }^{43}$ Consequently, the integration of other clinical risk factors with BMD to determine a 10-year absolute fracture risk can better assess the "gradient of risk" and in some circumstances help to determine the need for pharmacotherapy. ${ }^{40,44}$

A number of risk stratification tools have been developed to combine the independent risks from BMD and other clinical risk factors. Perhaps the most widely used risk assessment tool to date is the World Health Organization (WHO) fracture risk assessment (FRAX) model, ${ }^{45}$ which provides a 10-year absolute fracture risk estimate based on global observational epidemiologic data. Specified clinical risk factors (including age, prior fragility fracture, family history of hip fracture, cigarette smoking, excess alcohol intake, rheumatoid arthritis, and other secondary causes of bone loss) and DXA femoral neck (FN) BMD are required for inputting to a Web program, an iPhone application, or 
directly into densitometer software. The concept of 10-year absolute fracture risk is simple to understand and provides meaningful information for determining fragility fracture risk and the need for osteoporosis treatment.

\section{Adherence to osteoporosis therapies}

Adherence to oral osteoporosis therapy may be suboptimal due to strict dosing requirements, as well as possible intolerance to therapy. Generally, patients prefer and adhere more to less frequent dosing of their osteoporosis medication. ${ }^{46-50}$ Subcutaneous and intravenous administration may avoid perceived AEs associated with oral dosing, and adherence may be enhanced due to the need for a health care professional to administer the medication.

There are now a variety of dosing schedules and routes of administration for osteoporosis therapies allowing the tailoring of therapy to an individual's needs and desires. These choices may provide opportunities for improved adherence to therapy. In Canada, in addition to daily therapies (alendronate, risedronate, teriparatide, raloxifene, calcitonin, and hormone therapy), there are cyclical (etidronate), weekly (alendronate, risedronate), monthly (risedronate, ibandronate), twice-yearly (subcutaneous denosumab; under regulatory review), and yearly (intravenous zoledronic acid) therapies.

Therapies dosed less frequently and with fewer AEs may result in improved long-term adherence.

\section{Pharmacology, mode of action, and pharmacokinetics of denosumab}

The protein RANK is a transmembrane receptor of the tumor necrosis factor (TNF) superfamily on the surface of osteoclast precursors and mature osteoclasts. This receptor is also expressed in many other tissues, including chondrocytes, mammary gland epithelial cells, trophoblast cells, dendritic cells, and mature T cells. ${ }^{51}$

The protein RANKL is secreted and expressed primarily by preosteoblastic and osteoblastic cells. It is also expressed by endothelial cells, stromal cells, primitive mesenchymal cells surrounding cartilage, chondrocytes, activated T-lymphocytes, and immature CD4or CD8 thymocytes. ${ }^{51}$

The protein RANKL binds to its receptor, RANK, which results in osteoclast differentiation, fusion, maturation, activation, or survival. ${ }^{52-60}$ The RANKL knockout mice (no RANKL gene expression) have an absence of osteoclasts and severe osteopetrosis. ${ }^{61}$ In preclinical studies, inhibition of RANKL resulted in increased BMD, bone volume, and bone strength. ${ }^{62-68}$ In almost all diseases associated with excessively high rates of bone resorption, the RANK-RANKL pathway has been demonstrated to play a crucial role in the recruitment and activation of osteoclasts, leading to significant, rapid losses in bone mass: osteoporosis, ${ }^{69-71}$ Paget's disease, ${ }^{72}$ rheumatoid arthritis, ${ }^{73-77}$ psoriatic arthritis, ${ }^{78}$ prostate cancer, ${ }^{79,80}$ multiple myeloma, ${ }^{81-85}$ breast cancer-associated bone metastases, ${ }^{81,86-89}$ bone pain associated with bone metastases, ${ }^{90-93}$ giant cell tumors, ${ }^{94}$ and periprosthetic bone loss. ${ }^{75}$

The osteoprotegerin (OPG), a soluble member of the TNF-receptor family, is an endogenous neutralizing decoy receptor that competitively binds to RANKL, preventing its binding to RANK and thereby preventing osteoclast maturation and activity. ${ }^{62,95-97}$ Although the OPG is primarily expressed by mature osteoblasts, it is also released by dendritic cells and lymphocytes. ${ }^{51}$

In rodent models, OPG administration quickly decreases bone resorption. ${ }^{67}$ Clinical trials involving OPG or Fc-osteoprotegerin fusion protein (Fc-OPG) are not feasible and have been abandoned in favor of a fully human monoclonal antibody targeted to RANKL, ie, denosumab. Denosumab binds to RANKL and inhibits the activation of RANK in a similar fashion to OPG. Compared to Fc-OPG, denosumab is more potent (higher affinity), more specific to RANKL, and possesses a longer half-life at equivalent doses. ${ }^{98}$

Following subcutaneous injection, systemic absorption of denosumab is likely by the lymphatic system with subsequent distribution to the vascular system. Elimination is through metabolism, in the same manner as endogenous antibodies, with little renal excretion.

The pharmacokinetics of denosumab in a dose-escalation study was evaluated and was found to be nonlinear, with 3 distinct phases. ${ }^{98}$ The first phase is a prolonged absorption phase leading to maximal serum concentrations of denosumab within 5-21 days; maximal serum concentrations increased disproportionately greater than the increase in the dose (2.6-fold). The second phase was typified by a prolonged $\beta$-phase, which increased with doses up to a maximal 32 days. The last phase was a rapid terminal phase observed at concentrations of $1000 \mathrm{mg} / \mathrm{mL}$ with a half-life that increased from 5 to 10 days as dose increased from 0.01 to $3.0 \mathrm{mg} / \mathrm{kg}$. The mean serum residence time increased with the doses studied, ranging from 12 to 46 days.

\section{Denosumab efficacy in postmenopausal osteoporosis}

Denosumab trials conducted in postmenopausal women have demonstrated the potent antiresorptive properties of this antibody through reductions in bone turnover markers (BTMs); increases in BMD; improvement in biomechanically calculated 
strength; and reductions in the risk of vertebral, nonvertebral, and hip fractures in patients at risk. A comprehensive summary of the relevant clinical trials can be found in Table 1 .

\section{Biochemical markers of bone turnover}

Postmenopausal osteoporosis is often accompanied by high bone turnover, in part resulting from the decreases in endogenous estrogen associated with menopause. Decreased circulating estrogen in a postmenopausal woman results in increased number and activity of osteoclasts mediated by the RANK RANKL - OPG pathway. ${ }^{99,100}$ Higher rates of bone resorption over bone formation lead to losses in BMD, particularly in the first decade following the menopause. ${ }^{101}$ The effectiveness of an antiresorptive therapy, such as denosumab, can be estimated by BTMs, and they can also help in determining the therapy's duration of effect on bone turnover.

In a placebo-controlled study of denosumab to assess its safety and antiresorptive efficacy in postmenopausal women, ${ }^{98}$ placebo or subcutaneous denosumab injection at doses of $0.01,0.03,0.1,0.3,1.0$, or $3.0 \mathrm{mg} / \mathrm{kg}$ was administered. Urinary cross-linked N-telopeptide of type I collagen (uNTX; a bone resorption marker), serum NTX (sNTX), and serum bone-specific alkaline phosphatase (BALP; a bone formation marker) were assessed at several time points. Denosumab rapidly decreased bone resorption; after a single dose of denosumab, there was a dose-dependent decrease in both uNTX and sNTX levels. After 24 hours, the highest dose group of denosumab displayed a mean $73 \%$ decrease

Table I Phase 2 and phase 3 trials assessing the efficacy and safety of denosumab in osteopenic and osteoporotic postmenopausal women

\begin{tabular}{|c|c|c|c|c|c|}
\hline \multirow{2}{*}{$\begin{array}{l}\text { Lead author, year, } \\
\text { study acronym }\end{array}$} & \multicolumn{5}{|l|}{ Baseline } \\
\hline & Duration & Cohorts & Sample size & $\mathrm{Ca}$ and vit $\mathrm{D} / \mathrm{d}$ & Women mean age, y \\
\hline Bekker, $2004^{98}$ & $6-9 \mathrm{mo}$ & $\begin{array}{l}\text { DB: Dose-ranging } \\
\text { PBO: SC injection }\end{array}$ & $\begin{array}{l}\text { DB: } 37 \\
\text { PBO: } 12\end{array}$ & $\begin{array}{l}\text { Ca: } 0 \mathrm{~g} \\
\text { Vit D: } 0 \text { IU }\end{array}$ & $\begin{array}{l}\text { DB: } 58.8-63.3 \\
\text { PBO: } 54.3\end{array}$ \\
\hline McClung, $2006^{102}$ & Iy & $\begin{array}{l}\text { DB: Dose-rangingb } \\
\text { PBO: SC injection } \\
\text { ALN: } 70 \text { mg/wk }\end{array}$ & $\begin{array}{l}\text { DB: } 319 \\
\text { PBO: } 46 \\
\text { ALN: } 47\end{array}$ & $\begin{array}{l}\text { Ca: I g } \\
\text { Vit D: } 400 \text { IU }\end{array}$ & $\begin{array}{l}\text { DB: } 60.5-64.7 \\
\text { PBO: } 63.7 \\
\text { ALN: } 62.8\end{array}$ \\
\hline Lewiecki, $2008^{103}$ & $2 y$ & $\begin{array}{l}\text { DB: Dose-ranging } \\
\text { PBO: SC injection } \\
\text { ALN: } 70 \text { mg/wk }\end{array}$ & & & \\
\hline Miller, 2009104 & $4 y$ & $\begin{array}{l}\text { DB: } 60 \text { mg Q6m } \\
\text { PBO: SC injection } \\
\text { ALN: discontinued }\end{array}$ & & & \\
\hline Bone, 2008, DEFEND ${ }^{105}$ & $2 y$ & $\begin{array}{l}\text { DB: } 60 \text { mg Q6m } \\
\text { PBO: SC injection }\end{array}$ & $\begin{array}{l}\text { DB: } 166 \\
\text { PBO: } 166\end{array}$ & $\begin{array}{l}\text { Ca: } \geq \mathrm{I} g \\
\text { Vit D: } \geq 400 \mathrm{IU}\end{array}$ & $\begin{array}{l}\text { DB: } 59.8 \\
\text { PBO: } 59.8\end{array}$ \\
\hline Brown, 2009, DECIDE ${ }^{106}$ & Iy & $\begin{array}{l}\text { DB: } 60 \text { mg Q6m, PBO tablets } \\
\text { ALN: } 70 \text { mg/wk, SC PBO } \\
\text { injection }\end{array}$ & $\begin{array}{l}\text { DB: } 594 \\
\text { ALN: } 595\end{array}$ & $\begin{array}{l}\text { Ca: } \geq 0.5 \mathrm{~g} \\
\text { Vit D: } \geq 400 \mathrm{IU}\end{array}$ & $\begin{array}{l}\text { DB: } 64.1 \\
\text { ALN: } 64.6\end{array}$ \\
\hline $\begin{array}{l}\text { Cummings, } 2009 \text {, } \\
\text { FREEDOM } 117\end{array}$ & $3 y$ & $\begin{array}{l}\text { DB: } 60 \text { mg Q6m } \\
\text { PBO: SC injection }\end{array}$ & $\begin{array}{l}\text { DB: } 3933 \\
\text { PBO: } 3935\end{array}$ & $\begin{array}{l}\text { Ca: I g } \\
\text { Vit D: } \geq 400 \mathrm{IU}\end{array}$ & $\begin{array}{l}\text { DB: } 73.2 \\
\text { PBO: } 72.3\end{array}$ \\
\hline Kendler, 2010, STAND ${ }^{107}$ & Iy & $\begin{array}{l}\text { DB: } 60 \text { mg Q6m, PBO tablets } \\
\text { ALN: } 70 \text { mg/wk, SC } \\
\text { PBO injection }\end{array}$ & $\begin{array}{l}\text { DB: } 253 \\
\text { ALN: } 25 \text { I }\end{array}$ & $\begin{array}{l}\text { Ca: I g } \\
\text { Vit D: } \geq 400 \text { IU }\end{array}$ & $\begin{array}{l}\text { DB: } 66.9 \\
\text { PBO: } 68.2\end{array}$ \\
\hline Seeman, $2010^{128}$ & Iy & $\begin{array}{l}\text { DB: } 60 \mathrm{mg} \text { Q6m, PBO tablets } \\
\text { PBO: PBO SC injection } \\
\text { and tablets } \\
\text { ALN: } 70 \mathrm{mg} / \mathrm{wk}, \mathrm{SC} \\
\text { PBO injection }\end{array}$ & $\begin{array}{l}\text { DB: } 83 \\
\text { PBO: } 82 \\
\text { ALN: } 82\end{array}$ & $\begin{array}{l}\text { Ca: } \geq 0.5 \mathrm{~g} \\
\text { Vit D: } \geq 400 \mathrm{IU}\end{array}$ & $\begin{array}{l}\text { DB: } 60.3 \\
\text { PBO: } 60.8 \\
\text { ALN: } 60.7\end{array}$ \\
\hline
\end{tabular}


in uNTX (a 10\% decrease in the placebo group). Maximum uNTX reduction occurred 2 weeks after the injection in the 4 lowest-dose groups and after 1 month in the 2 highestdose groups ( $84 \%$ bone resorption suppression as compared to baseline). Reversibility of denosumab treatment was observed after maximum suppression of resorption, with slow return toward baseline. The levels of BALP remained unchanged until the third week following the subcutaneous injection of denosumab after which dose-dependent decreases were noted. A maximum mean change was attained 5 months after denosumab injection in the highest-dose group (53\% decrease vs $8 \%$ increase in placebo), with a mean decrease of $37 \%$ after 9 months (33\% decrease in placebo). The temporal difference between suppression in resorption and formation of markers was expected since bone resorption and formation are linked to bone remodeling and follow one another in time. This trial demonstrated that a single injection of denosumab can lead to rapid and sustained decreases in bone turnover in a dose-dependent and reversible manner.

The phase 2 denosumab trials in postmenopausal women with low BMD were dose-ranging ${ }^{102}$ with random, blind assignment to 1 of 8 groups (denosumab subcutaneous 6,14 , or $30 \mathrm{mg}$ every 3 months; denosumab subcutaneous 14,60 , 100 , or $210 \mathrm{mg}$ every 6 months; or placebo) or open-label alendronate $(70 \mathrm{mg} / \mathrm{wk})$ for, initially, 1 year. Three days after denosumab injection, serum C-telopeptide cross-links of type I collagen (sCTX) decreased significantly as compared to placebo (for changes in SCTX in all available trials, see

Table I (Continued)

\begin{tabular}{|c|c|c|}
\hline Mean BMD T-score & Percent follow-up & Primary outcome and secondary outcomes \\
\hline NA & $100 \%$ & $\begin{array}{l}\mathrm{I}^{\circ}: \% \Delta \mathrm{uNTX} \text { and BALP during } 6-9 \text { mo follow-up after single SC injection } \\
2^{\circ}: \Delta \text { in sCa and iPTH during 6-9 mo follow-up after single SC injection }\end{array}$ \\
\hline LS: from -2.0 to -2.3 & $90 \%$ & $\mathrm{I}^{\circ}: \% \Delta \mathrm{LS} B M D$ at $12 \mathrm{mo}$ \\
\hline \multicolumn{2}{|l|}{ TH: from $-\mathrm{I} .3$ to $-\mathrm{I} .5$} & $2^{\circ}: \% \Delta \mathrm{TH}, \mathrm{FN}, \mathrm{TB}$, and OTR BMD and $\% \Delta$ in sCTX, uNTX, and BALP after 12 mo \\
\hline \multicolumn{3}{|l|}{ FN: from -1.7 to -2.0} \\
\hline & \multirow[t]{2}{*}{$82 \%$} & $\mathrm{I}^{\circ}: \% \Delta \mathrm{LS} B M D$ at $12 \mathrm{mo}$ \\
\hline & & $2^{\circ}: \% \Delta \mathrm{LS}, \mathrm{TH}, \mathrm{FN}, \mathrm{TB}$, and OTR BMD and $\% \Delta$ in sCTX, uNTX, and BALP after 24 mo \\
\hline & \multirow[t]{2}{*}{$64 \%$} & $\mathrm{I}^{\circ}: \% \Delta \mathrm{LS} B M D$ at $12 \mathrm{mo}$ \\
\hline & & $2^{\circ}: \% \Delta \mathrm{LS}, \mathrm{TH}, \mathrm{FN}, \mathrm{TB}$, and OTR BMD and sCTX, uNTX, and BALP after 48 mo \\
\hline DB LS: -1.55 & \multirow[t]{2}{*}{$86 \%$} & $\mathrm{I}^{\circ}: \% \Delta \mathrm{LS} B M D$ at $24 \mathrm{mo}$ \\
\hline PBO LS: -1.66 & & $2^{\circ}: \% \Delta \mathrm{TH}, \mathrm{FN}, \mathrm{OTR}$, and TB BMD at $24 \mathrm{mo}$ and $\% \Delta$ in QCT-assessed distal radius BMD at $24 \mathrm{mo}$ \\
\hline DB LS: -2.57 & \multirow[t]{4}{*}{$94 \%$} & $\mathrm{I}^{\circ}: \% \Delta \mathrm{TH} B M D$ at 12 mo equal between $\mathrm{DB}$ and $\mathrm{ALN}$ \\
\hline ALN LS: -2.57 & & $2^{\circ}: \mathrm{DB}>\mathrm{ALN}$ of TH and OTR BMD at $12 \mathrm{mo}, \mathrm{DB}=\mathrm{ALN}$ GT, FN, LS BMD at $12 \mathrm{mo}$ \\
\hline \multicolumn{2}{|l|}{ DB TH: -1.75} & \\
\hline \multicolumn{2}{|l|}{ ALN TH: -1.69} & \\
\hline LS: -2.8 & \multirow[t]{3}{*}{$82 \%$} & $\mathrm{I}^{\circ}:$ new vert $\mathrm{fx}$ after $36 \mathrm{mo}$ \\
\hline TH: -1.9 & & $2^{\circ}:$ time to first non vert $f x$, time to first hip fx \\
\hline \multicolumn{2}{|l|}{ FN: -2.2} & \\
\hline DB LS: -2.64 & \multirow[t]{4}{*}{$95 \%$} & $\mathrm{I}^{\circ}: \% \Delta \mathrm{TH} B M D$ at $12 \mathrm{mo}$ \\
\hline ALN LS: -2.62 & & $2^{\circ}: \% \Delta$ in sCTX at $3 \mathrm{~m}$ and $\% \Delta$ LS BMD at $12 \mathrm{mo}$ \\
\hline \multicolumn{2}{|l|}{ DB TH: -1.79} & \\
\hline \multicolumn{2}{|l|}{ ALN TH: $-I .8 I$} & \\
\hline $\begin{array}{l}\text { DB LS: }-2.4 \\
\text { PBO LS: }-2.4 \\
\text { ALN LS: }-2.5 \\
\text { DB TH: }-1.4 \\
\text { PBO TH: }-1.1 \\
\text { ALNTH: }-1.4\end{array}$ & $88 \%$ & $\begin{array}{l}\text { Exploratory efficacy end points: } \% \Delta \text { as assessed by HR-pQCT at distal radius and tibia in total, } \\
\text { trabecular and cortical volumetric BMD, cortical thickness, trabecular number, thickness, and } \\
\text { separation; } \% \Delta \text { as assessed by QCT in volumetric BMD and polar moment of inertia; } \% \Delta \text { in } \\
\text { sCTX and PINP }\end{array}$ \\
\hline \multicolumn{3}{|c|}{$\begin{array}{l}\text { cPrior } 30 \mathrm{mg} \mathrm{Q3m} \mathrm{DB} \mathrm{dose} \mathrm{was} \mathrm{discontinued} \mathrm{for} \mathrm{year} 3 \text { and restarted on } 60 \mathrm{mg} \text { Q6m in year 4, prior DB dose } 210 \text { mg every } 6 \text { months was discontinued for years } 3 \text { and } 4 \text {, } \\
\text { all other prior DB doses were switched to } 60 \mathrm{mg} \text { Q6m for years } 3 \text { and } 4 .\end{array}$} \\
\hline \multicolumn{3}{|c|}{$\begin{array}{l}\text { Abbreviations: DB, denosumab; ALN, alendronate; PBO, placebo; SC, subcutaneous; } 60 \text { mg Q6m, } 60 \text { mg subcutaneously every } 6 \text { months; BMD, bone mineral density; LS, } \\
\text { lumbar spine; TH, total hip; FN, femoral neck; TB, total body; OTR, distal one-third radius; GT, greater trochanter; Ca and Vit D/d, daily calcium and vitamin D supplementation; }\end{array}$} \\
\hline \multicolumn{3}{|c|}{$\begin{array}{l}\mathrm{I}^{\circ} \text {, primary outcome; } 2^{\circ} \text {, secondary outcomes; fx, fracture; vert, vertebral; NA, not available/not applicable; } \Delta \text {, change; uNTX, urinary cross-linked N-telopeptide of type I } \\
\text { collagen; BALP, bone-specific alkaline phosphatase; sCTX, serum C-telopeptide cross-links of type I collagen; QCT, quantitative computed tomography; HR-pQCT, high- } \\
\text { resolution peripheral QCT; PINP, procollagen type I N-terminal propeptide; sCa, serum calcium; iPTH, intact serum parathyroid hormone. }\end{array}$} \\
\hline
\end{tabular}


Figure 1, and for changes in bone formation markers, see Figure 2; note that in all figures data points were extracted from primary publications as accurately as possible). The maximum mean decrease in resorption of the denosumab groups was $88 \%$ (vs 6\% decrease with placebo), with larger doses suppressing turnover for a longer period of time, on average. The uNTX and SCTX results were similar. The bone formation markers (ie, BALP) showed a similar pattern of suppression, which was delayed for 1 month after the bone resorption marker decline. Alendronate reduced resorption markers to a similar magnitude, albeit more slowly than denosumab.

In the second year of this trial, BTMs showed stable suppression of bone turnover with partial release just prior to the next denosumab injection. Progressive suppression was not seen, and there was no evidence of tachyphylaxis. ${ }^{102,103}$ Four-year follow-up of this cohort ${ }^{102-104}$ involved crossing some patients previously on other doses of denosumab over to active therapy with denosumab $60 \mathrm{mg}$ every 6 months (60 mg Q6m). Some patients who were treated with denosumab for the initial 2 years were crossed over to placebo.
The open-label alendronate group discontinued therapy, and the placebo group continued placebo through year 4. ${ }^{104}$

In the cohort that continued denosumab (60 mg Q6m), BTM suppression continued similar to the initial 2 years of therapy.

The group that discontinued denosumab showed rebound increases above baseline BTMs in year 3 with a return to baseline levels after year 4 , demonstrating the reversibility of denosumab with return to baseline BTM status.

Following a year off denosumab therapy, re-treatment in the fourth year rapidly reduced BTMs similar to treatmentnaive patients. ${ }^{104}$

After discontinuation of alendronate, there was a slow increase in BTMs toward baseline; however, levels remained significantly lower than baseline after 2 years off therapy. Differences in reversibility between alendronate and denosumab may relate to the difference in mechanism of action between the 2 drugs, as well as differences in the elimination of the medications. Alendronate, through its incorporation in bone tissue, likely persists for many months to years with residual effects on bone and the cells that act on it.

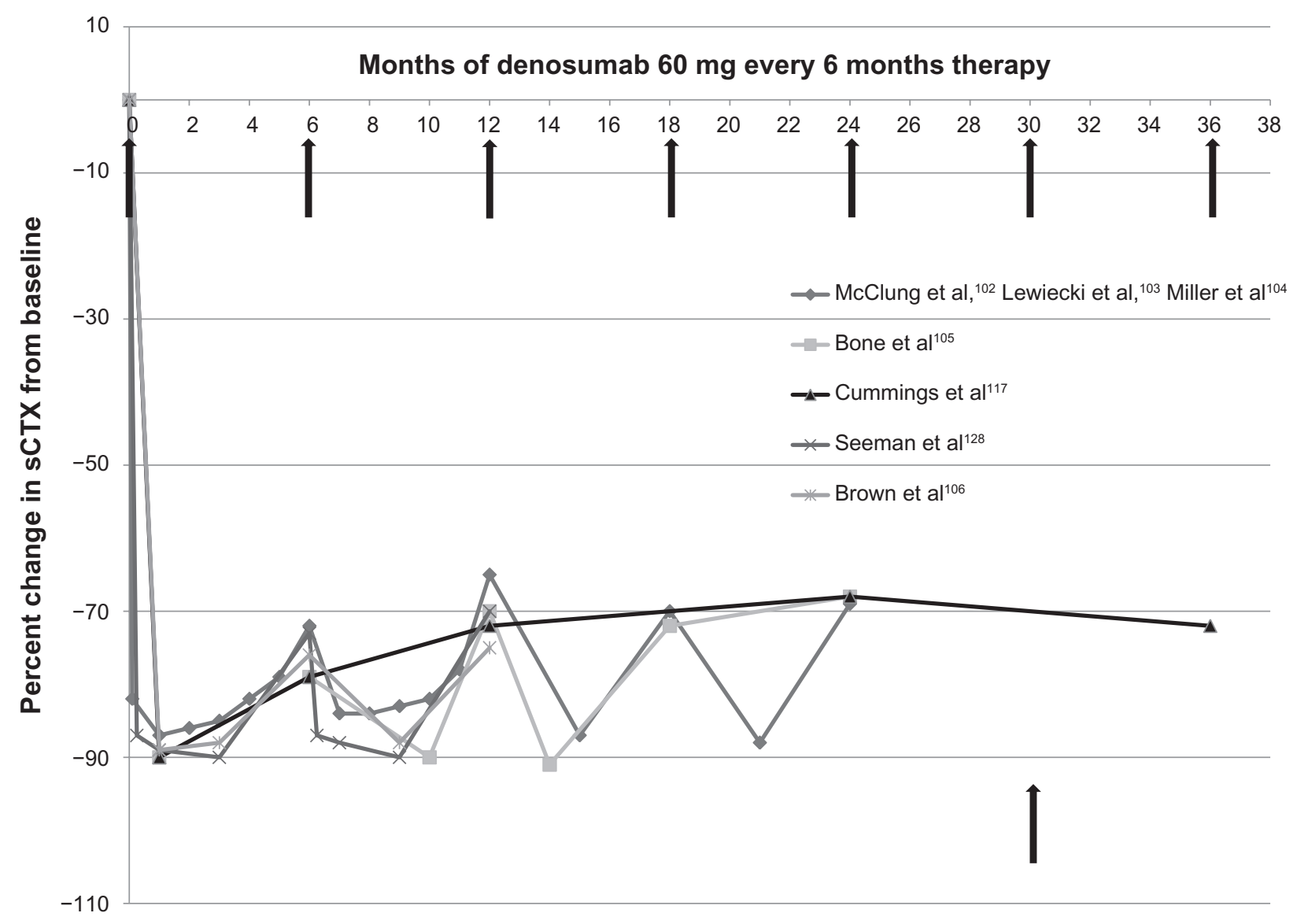

Figure I Percent change in serum C-telopeptide cross-links of type I collagen (sCTX) from baseline after denosumab administration in phase 2 and 3 clinical trials in postmenopausal women with low bone mass. All data represent the 60 -mg denosumab every 6 months dose. 


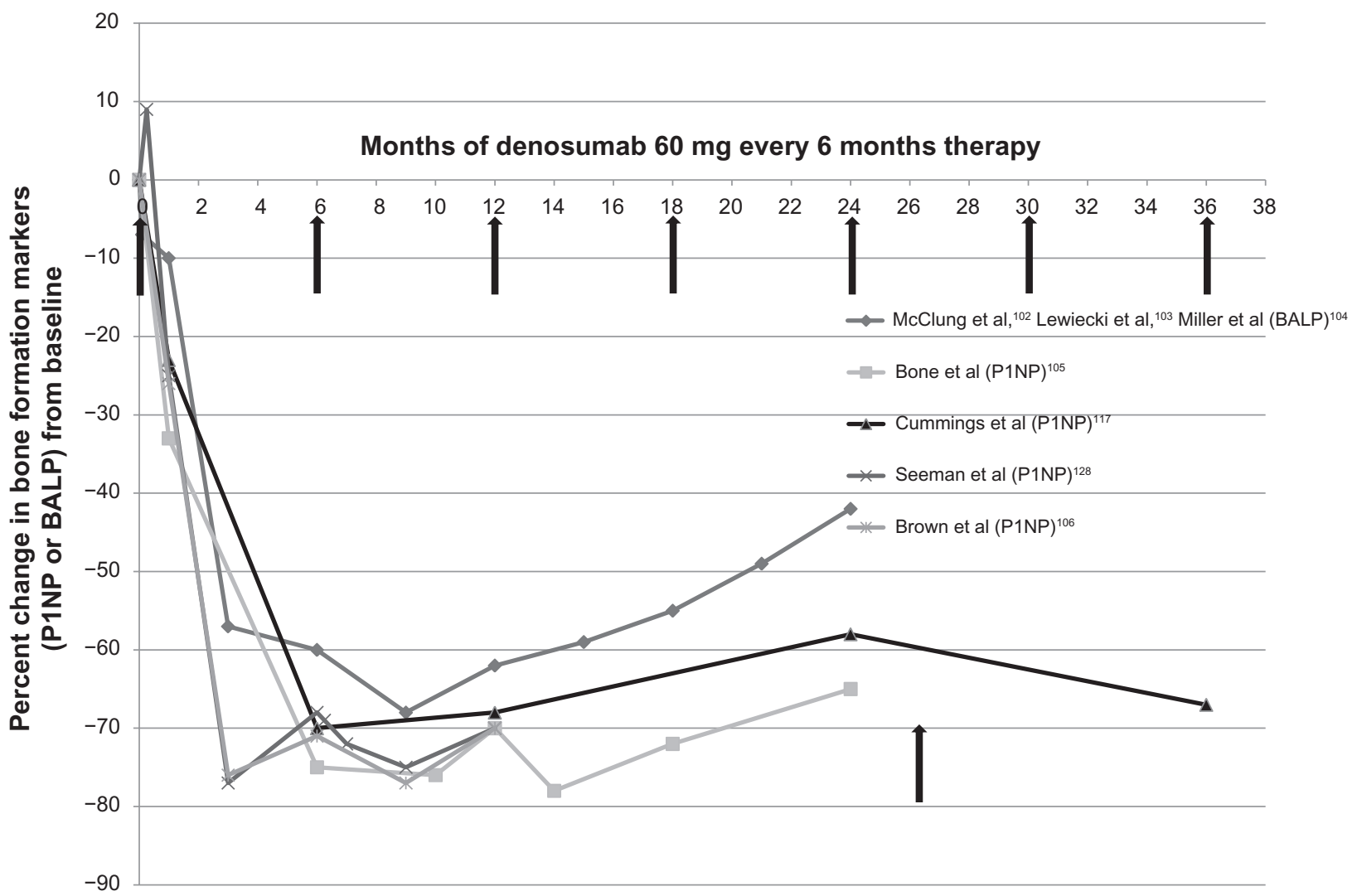

Figure 2 Percent change in procollagen type I intact $\mathrm{N}$-terminal propeptide (PINP) or bone-specific alkaline phosphatase (BALP) from baseline after denosumab administration in phase 2 and 3 clinical trials in postmenopausal women with low bone mass. All data represent the 60-mg denosumab every 6 months dose.

The role of denosumab in the prevention of postmenopausal bone loss was investigated in the Denosumab Fortifies Bone Density (DEFEND) trial in which 60 mg Q6m denosumab or placebo was administered to a cohort of osteopenic postmenopausal women. ${ }^{105}$ The sCTXs, serum band 5 tartrate-resistant acid phosphatase (TRAP-5b; a bone resorption marker) and serum procollagen type I intact $\mathrm{N}$-terminal propeptide (P1NP; a bone formation marker), were assessed at baseline and at various time points. The BTMs were rapidly reduced by denosumab with SCTX reaching a nadir within 1 month (median, $89 \%$ reduction) and remained at this level thereafter. The reductions in TRAP-5b were similar to those in SCTX. The level of P1NP was reduced by $32 \%$ with denosumab treatment at 1 month, and there were eventual reductions of $65 \%-76 \%$ during the 2 years (vs $4 \%-15 \%$ reductions in the placebo group). This trial demonstrated that denosumab rapidly decreased bone turnover in osteopenic women.

The Determining Efficacy: Comparison of Initiating Denosumab vs Alendronate (DECIDE) trial was a randomized head-to-head comparison of denosumab (60 mg Q6m) and alendronate $(70 \mathrm{mg} / \mathrm{wk})$ over 1 year. ${ }^{106}$ BTMs were reduced with both therapies, but to a greater magnitude in denosumab patients and with indication of release from bone turnover suppression prior to each 6-monthly injection. With denosumab therapy, decreases in SCTX were rapid with an $89 \%$ median decrease from baseline after 1 month compared to a median decrease of $61 \%$ for the alendronate group $(P<0.001)$. At all time points (except year 1$)$, the median suppression of SCTX was significantly greater $(P<0.001)$ in the denosumab group $(74 \%-89 \%)$ compared to the alendronate group (66\%-76\%). The level of P1NP decreased with both therapies, and there were significantly greater decreases with denosumab therapy at all time points. ${ }^{106}$

Bisphosphonates are retained in the skeleton for a prolonged period of time. Thus, it is important that safety and efficacy of other therapies in patients switching from bisphosphonates to other agents such as denosumab are evaluated. The Study of Transitioning from Alendronate to Denosumab (STAND) trial was a 1-year phase 3 trial that compared denosumab (60 mg Q6m) to alendronate $(70 \mathrm{mg} / \mathrm{wk})$ in postmenopausal women previously treated with alendronate for more than 6 months (median 36 months). ${ }^{107}$ Bone resorption 
(sCTX) in the alendronate group remained stably suppressed. In patients treated with denosumab, sCTX was significantly decreased as compared to baseline in as early as 5 days. The levels of sCTX and P1NP in patients on denosumab showed greater decreases compared to alendronate. This study demonstrated that after a median 3 years of alendronate therapy, denosumab was able to further rapidly reduce bone turnover.

Denosumab consistently decreased BTMs, with decreases of $70 \%-90 \%$ from baseline, and demonstrated reversibility with values drifting slightly upward just before the next scheduled denosumab dose (Figure 1). In other placebo-controlled trials, uNTX was reduced by alendronate by $56 \%-70 \%,{ }^{108,109}$ risedronate by $40 \%-61 \%,{ }^{110,111}$ zoledronic acid by $45 \%-65 \%,{ }^{112}$ and raloxifene by $17 \% .{ }^{113}$ The greater (and more rapid) reduction of BTMs with denosumab therapy in head-to-head trials with alendronate may be due to the difference in mechanism of action or to greater access of denosumab to cortical compartments of bone. The rapid onset of the action of denosumab suggests that active, mature osteoclasts are inhibited almost immediately after treatment. ${ }^{98}$ Finally, on discontinuation of denosumab, BTMs return back to baseline within a few months, demonstrating its reversibility. ${ }^{104}$

\section{Bone mineral density}

Treatment with denosumab results in increases in BMD at all measured sites. Figures 3, 4, and 5 present the change in BMD from baseline of the lumbar spine (LS), total hip (TH), and distal one-third radius (OTR) when treated with $60 \mathrm{mg}$ Q6m denosumab for all applicable postmenopausal osteoporosis trials.

In a phase 2 study, ${ }^{102}$ there was a $0.8 \%$ mean decrease in LS BMD with the placebo group compared to increases of $3.0 \%-6.7 \%$ in the denosumab groups, depending on dose, after 1 year (all $P<0.001$ vs placebo). Similar results were seen for TH (denosumab: $1.9 \%-3.6 \%$ vs placebo: $-0.6 \% ; P<0.001$ ), OTR (denosumab: $0.4 \%-1.3 \%$ vs placebo: $-2.0 \% ; P<0.001$ ), and total body (TB; denosumab: $0.6 \%-2.8 \%$ vs placebo: $-0.2 \%$; $P<0.01$, except $14 \mathrm{mg}$ denosumab every 6 months). Some denosumab groups (including $60 \mathrm{mg}$ Q6m) increased LS BMD significantly in as little as 1 month, compared to placebo $(P<0.05)$. There were significantly greater gains in BMD with

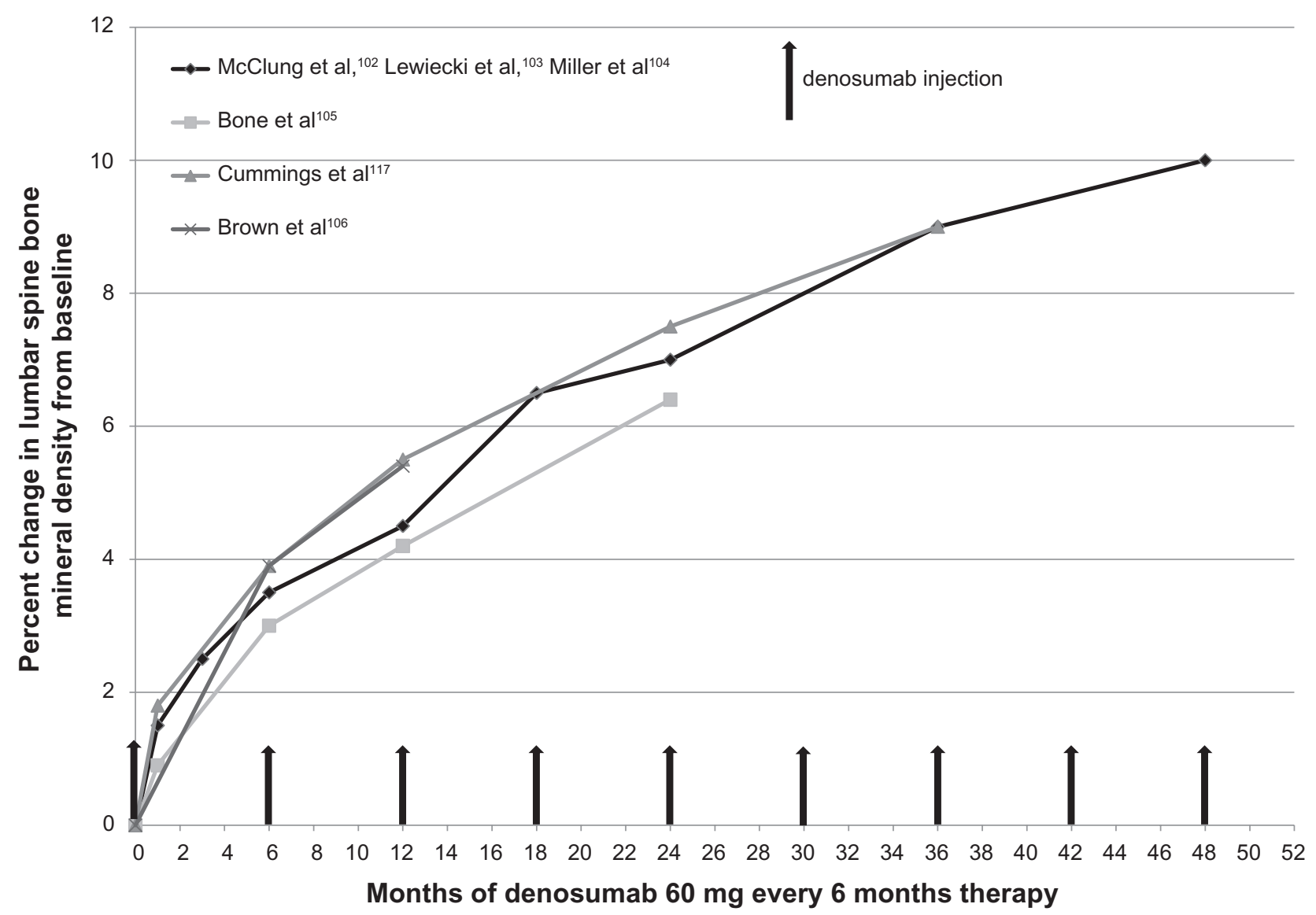

Figure 3 Percent change in lumbar spine bone mineral density from baseline after denosumab administration in phase 2 and 3 clinical trials in postmenopausal women with low bone mass. All data represent the $60-\mathrm{mg}$ denosumab every 6 months dose. 


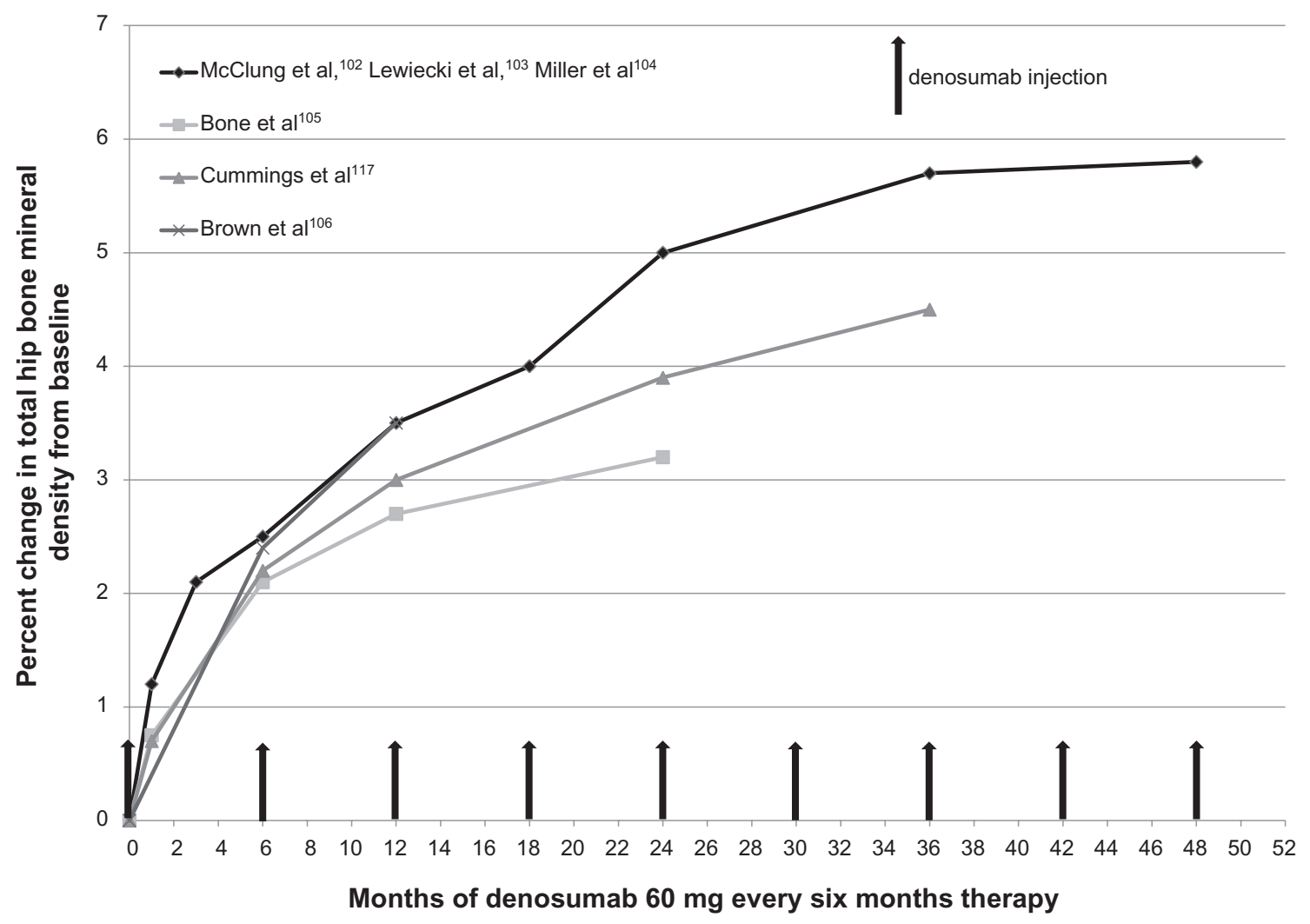

Figure 4 Percent change in total hip bone mineral density from baseline after denosumab administration in phase 2 and 3 clinical trials in postmenopausal women with low bone mass. All data represent the 60 -mg denosumab every 6 months dose.

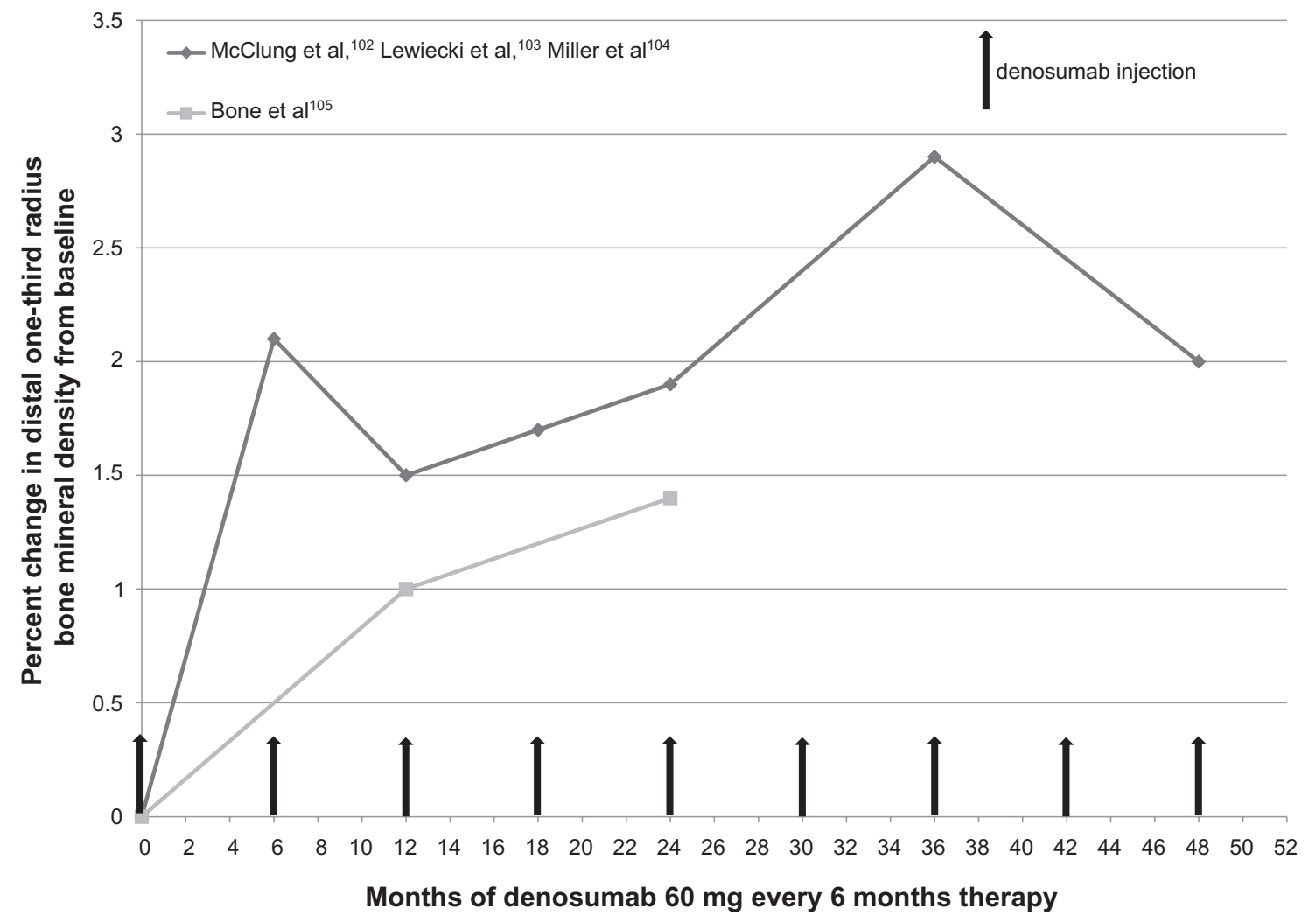

Figure 5 Percent change in distal one-third radius bone mineral density from baseline after denosumab administration in phase 2 and 3 clinical trials in postmenopausal women with low bone mass. All data represent the 60-mg denosumab every 6 months dose. 
denosumab (as compared to alendronate) at the more-cortical OTR and TH sites. ${ }^{102}$

There were further significant increases in BMD with denosumab at all sites after 2 years of therapy $(P<0.001) .{ }^{103}$ Lumbar spine BMD was greater than placebo in as early as 3 months on denosumab therapy. Denosumab was associated with greater increases in BMD after 2 years of therapy than alendronate at all sites (except the $14 \mathrm{mg}$ every 6 months dose). The increases in BMD were independent of baseline BMD or baseline sCTX.

After 4 years, most patients on denosumab gained BMD at the LS and the $\mathrm{TH}$ sites (97\% and 96\%, respectively), whereas most of the placebo group lost BMD at these sites (72\% and $83 \%$, respectively). ${ }^{104}$ Denosumab patients had a 9.8\%-11.8\% increase in LS BMD, a 4.0\%-6.1\% increase in TH BMD, and a $1.0 \%-1.7 \%$ increase in OTR BMD over the 4 years compared to a mean decrease of $2.4 \%, 3.5 \%$, and $4.7 \%$ in the placebo group, respectively (all $P<0.001$ ).

In the group that discontinued denosumab after year 2 , there was a drop in BMD in the third year equivalent to the gain in the first 2 years of therapy; but the values were still higher than those for the group on placebo for 4 years. Re-treatment with denosumab after a year of discontinuation resulted in increases in BMD similar to those observed in the first 2 years of therapy. Discontinuation of alendronate led to modest declines in LS BMD by the end of year 4, and larger decreases in BMD at the TH and OTR.

In the DEFEND trial of denosumab in osteopenic women, the response to denosumab in LS BMD was rapid with significant differences from placebo at 1 month and at all time points thereafter (all $P<0.01$ ). ${ }^{105}$ There were significant increases in TH, FN, OTR, and TB BMD and in quantitative computed tomography (QCT)-assessed total volumetric BMD (vBMD), as compared to placebo after 2 years of denosumab therapy (all $P<0.01$ ). A total of $96 \%, 96 \%$, and $71 \%$ of the denosumab cohort gained LS, TH, and OTR BMD, respectively, whereas only $39 \%, 31 \%$, and $22 \%$ of the placebo group gained LS, TH, and OTR BMD respectively $(P<0.001)$. This trial demonstrated that denosumab rapidly and significantly increases BMD in osteopenic women.

In the phase 3 DECIDE study, ${ }^{106}$ a year of denosumab therapy increased TH BMD by a mean 3.5\% compared to a mean $2.6 \%$ increase in women treated with alendronate $(P<0.001)$. Significantly greater gains in BMD with denosumab vs alendronate were reported at the $\mathrm{FN}(2.4 \%$ vs $1.8 \%)$, trochanter $(4.5 \%$ vs $3.4 \%)$, LS (5.3\% vs $4.2 \%)$, and OTR $(1.1 \%$ vs $0.6 \%)$ sites after 1 year; the same was true at 6 months. This trial demonstrated denosumab's superiority in increasing BMD after a year as compared to alendronate; head-to-head trials vs risedronate or ibandronate have shown superior BMD increases with alendronate therapy. ${ }^{114-116}$

In the STAND trial, ${ }^{107}$ where patients previously on alendronate were transitioned to denosumab or maintained on alendronate, TH and LS BMD increased significantly more with denosumab (1.90\% and 3.30\%, respectively; $P<0.001)$ compared to alendronate ( $1.05 \%$ and $1.85 \%$, respectively); significantly greater gains with denosumab were also realized at the FN and OTR $(P<0.05)$. Again, significantly greater gains were measured in the denosumab group in as early as 6 months $(P<0.05$ at LS, TH, and FN). This study demonstrated that denosumab administration can increase BMD more rapidly and to a greater extent than alendronate continuation in patients who were previously stable on alendronate therapy.

As can be observed from Figures 3, 4, and 5, denosumab administration results in increases in BMD at all sites measured.

\section{Fracture}

The Fracture Reduction Evaluation of Denosumab in Osteoporosis Every Six Months (FREEDOM) trial was a phase 3 placebo-controlled trial that compared denosumab (60 mg Q6m) vs placebo in the prevention of fractures. ${ }^{117}$ Approximately, a quarter of the women under study had a prevalent vertebral fracture at baseline.

After 36 months, there was a $68 \%$ reduction in the risk of new vertebral fractures with denosumab therapy (relative risk $[R R]=0.32 ; 95 \%$ confidence interval $[\mathrm{CI}], 0.26-0.41$; absolute risk $=2.3 \%$ denosumab and $7.2 \%$ placebo) as compared to placebo, with similar reductions in risk for all 3 years of the trial. Similar 3-year reductions in fracture risk with denosumab therapy were calculated for new clinical vertebral fractures ( $69 \%$ reduction; hazard ratio $=0.31 ; 95 \%$ CI, $0.20-0.47$; absolute risk $=0.8 \%$ for denosumab and $2.6 \%$ for placebo), multiple new vertebral fractures (61\% reduction; $\mathrm{RR}=0.39 ; 95 \% \mathrm{CI}, 0.24-0.63$; absolute risk $=0.6 \%$ denosumab and $1.6 \%$ placebo), nonvertebral fractures $(20 \%$ reduction; hazard ratio $=0.80 ; 95 \% \mathrm{CI}, 0.67-0.95$; absolute risk $=6.5 \%$ denosumab and $8.0 \%$ placebo), and hip fractures $(40 \%$ reduction; hazard ratio $=0.60 ; 95 \%$ CI, 0.37-0.97; absolute risk $=0.7 \%$ denosumab and $1.2 \%$ placebo).

Although not in head-to-head comparison trials, the vertebral fracture risk reductions were similar to those reported for intravenous zoledronic acid but generally higher than reductions with oral bisphosphonates, ${ }^{118-122}$ and the nonvertebral reductions in fracture risk were comparable to those reported for alendronate, risedronate, and zoledronic acid. ${ }^{118-120}$ The efficacy of denosumab in decreasing vertebral, nonvertebral, and hip fracture risks 
compared to other osteoporosis medications (alendronate, ${ }^{118}$ etidronate, ${ }^{123}$ risedronate, ${ }^{124-126}$ teriparatide, ${ }^{127}$ and zoledronic acid ${ }^{119}$ ) are presented in Figures 6, 7, and 8, respectively. Although these data compare treatment in largely similar populations (older postmenopausal women), there are differences in baseline BMD and prior fracture history that can account for some of the observed differences in fracture risk reduction. Further, the absence of head-tohead fracture trials negates the possibility of conclusively comparing the antifracture therapies for their reductions in fracture risk.

After 3 years, there was a 9.2\% increase in LS BMD and a $6.0 \%$ increase at the $\mathrm{TH}$ as compared to placebo $(P<0.001)$. As with the other trials, the reduction in markers of bone turnover was rapid ( $86 \%$ reduction of sCTX in first month) and sustained (72\% reduced at 36 months). Similar trends were observed with P1NP, but with some lag (18\% reduced after 1 month and 76\% reduced after 36 months). ${ }^{117}$

\section{Bone strength and denosumab}

A phase 2 study was conducted over a 1-year period to assess the impact of alendronate $(70 \mathrm{mg} / \mathrm{wk}$ ) or denosumab (60 mg Q6m) compared to placebo on the microarchitectural components of bone as assessed by high-resolution peripheral QCT (HR-pQCT) at the wrist and distal tibia. ${ }^{128}$

At the distal radius, treatment with denosumab increased all vBMD measures and cortical thickness relative to baseline (significantly greater than alendronate for total and cortical vBMD) after 1 year, treatment with alendronate preserved vBMD and increased cortical thickness, and treatment with placebo resulted in losses in all measures of vBMD and in cortical thickness.

At the distal tibia, treatment with denosumab increased all vBMD measures and cortical thickness relative to baseline (significantly greater than alendronate for total and cortical vBMD) after 1 year; treatment with alendronate resulted in increased total and trabecular vBMD, maintained cortical vBMD, and resulted in increased cortical thickness; and treatment with placebo resulted in losses in all measures of vBMD and increased cortical thickness. Denosumab therapy increased vBMD significantly more than alendronate at most sites assessed by HR-pQCT.

In a post hoc analysis of a subset of DXA scans from the phase 2 trial, ${ }^{103}$ changes in bone structure and mechanical strength indices were investigated using hip structural analysis (HSA) in patients treated for 2 years with alendronate,

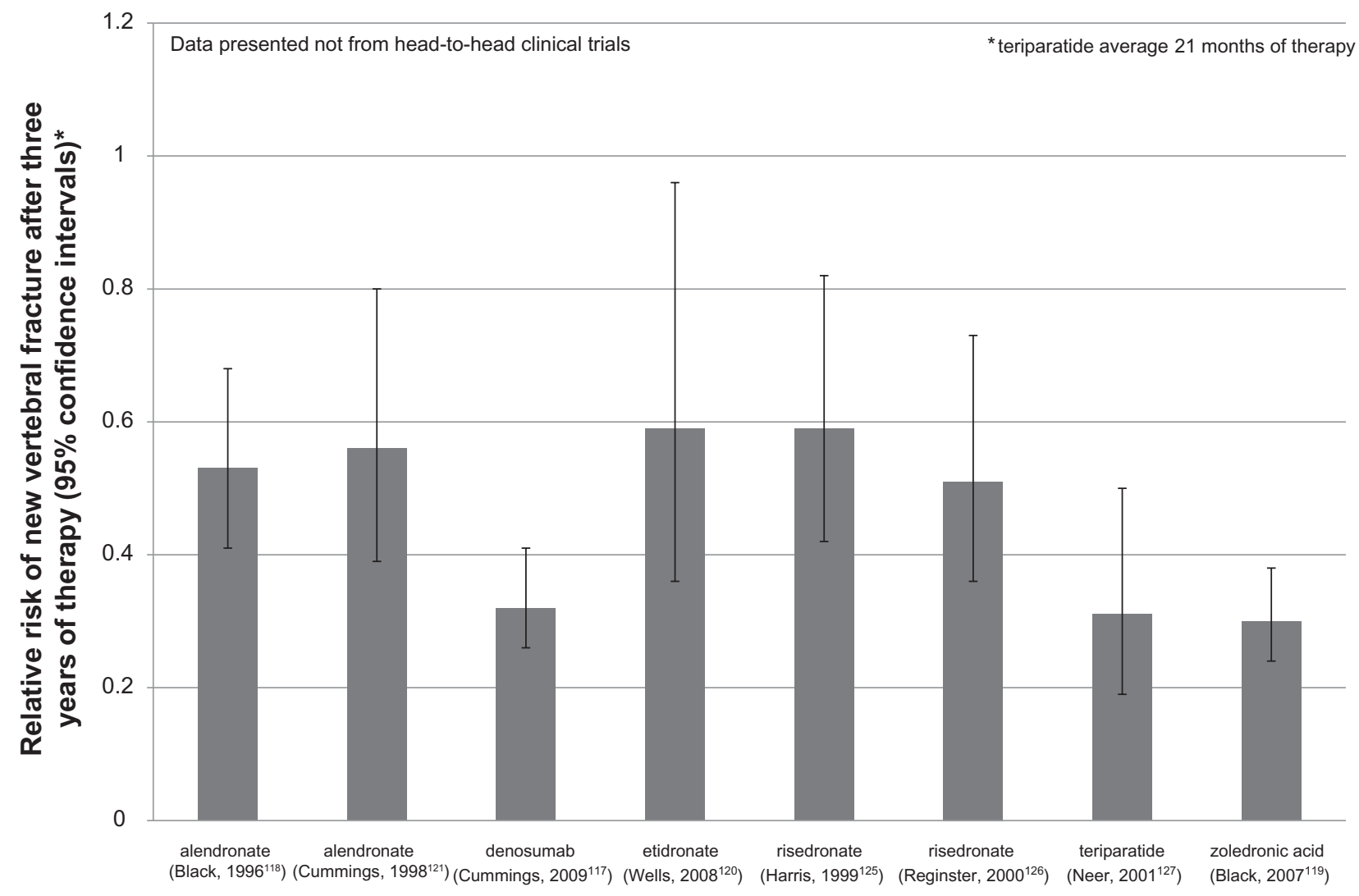

Anti-fracture therapy (lead author, year data published)

Figure 6 Relative risk of new vertebral fracture after 3 years of antifracture therapy. 


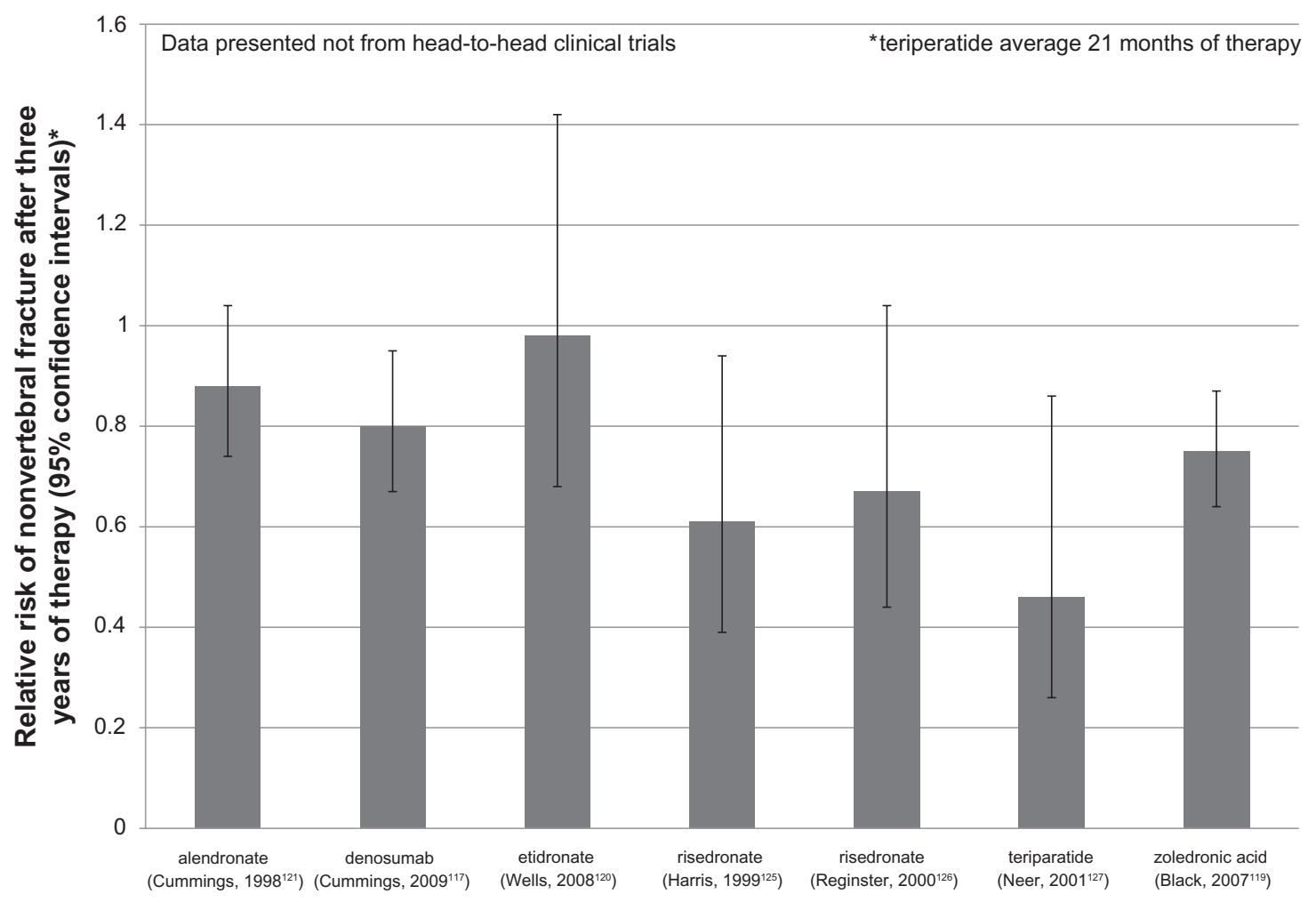

Anti-fracture therapy (lead author, year data published)

Figure 7 Relative risk of nonvertebral fracture after 3 years of antifracture therapy.

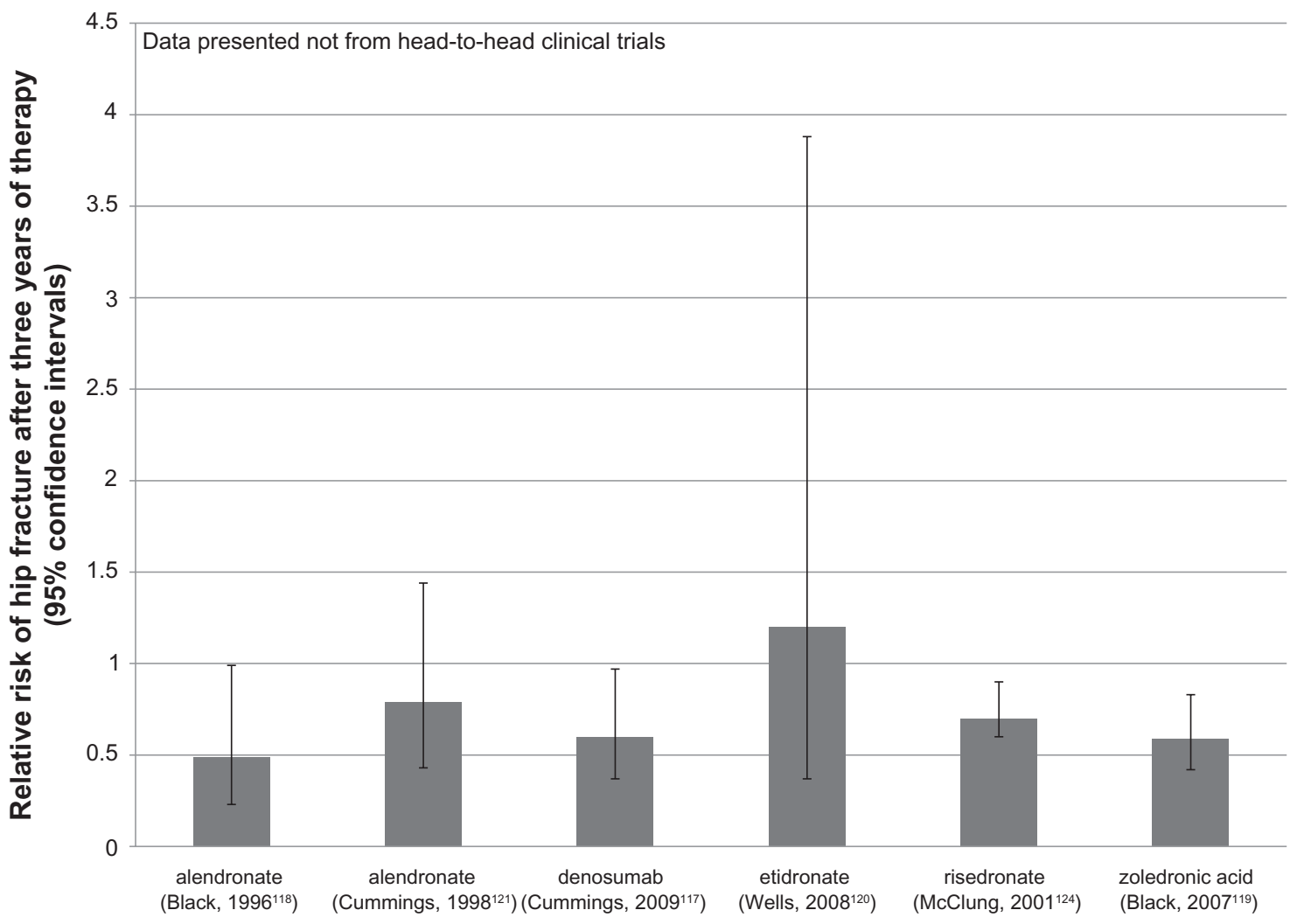

Anti-fracture therapy (lead author, year data published)

Figure 8 Relative risk of hip fracture after 3 years of antifracture therapy. 
denosumab, or placebo. ${ }^{129}$ At 12 and 24 months, both the alendronate and denosumab treatment groups had improved structure and strength measures compared to the placebo group. At the intertrochanteric and femoral shaft sites, the effect of denosumab was greater than that of alendronate. Similar HSA results were reported in the DEFEND trial in osteopenic women. ${ }^{105}$ These trials demonstrate that denosumab therapy leads to structural changes in bone that may be more beneficial to cortical bone strength than alendronate therapy.

\section{Denosumab for prevention of treatment-induced bone loss (hormone ablation therapy)}

Denosumab trials in patients with treatment-induced bone loss (hormone ablation therapy) have demonstrated the potent antiresorptive properties of denosumab through reductions in BTMs, increases in BMD, and reduction in the risk of new vertebral fractures. A comprehensive summary of the relevant clinical trials can be found in Table 2 .

\section{Denosumab and androgen ablation therapy}

Prevention of bone loss during ADT is important because if untreated, this patient population is at high risk of bone loss and fragility fracture. A randomized, double-blind, placebo-controlled phase 3 trial $^{130}$ evaluated the impact of denosumab (60 mg Q6m) or placebo on BMD and fractures in men receiving ADT for hormone-sensitive prostate cancer. With denosumab treatment, markers of bone resorption decreased rapidly and significantly and BMD increased at all measured sites. At the LS, there were significant increases in BMD at 1 month that continued through 3 years, with a $6.7 \%$ increase compared to the placebo group after 24 months $(P<0.001)$. There were significant increases in BMD compared to placebo at all other assessed sites and at all time points (TH, FN, OTR, and TB; $P<0.001$ ). Importantly, after 3 years of denosumab therapy, there was an RR reduction of $62 \%$ in new vertebral fractures compared to the placebo group $(\mathrm{RR}=0.38 ; 95 \% \mathrm{CI}, 0.19-0.78$; absolute risk $=1.5 \%$ denosumab and $3.9 \%$ placebo). This study demonstrated the ability of denosumab to rapidly decrease bone resorption, to significantly increase BMD at all sites assessed, and to decrease the incidence of new vertebral fractures by $62 \%$ in men treated for prostate cancer. Other studies on men with osteoporosis have demonstrated that oral bisphosphonates and teriparatide increase bone density to a similar degree as in the case of postmenopausal women treated with the same agents. ${ }^{131-134}$
In a subgroup analysis of the aforementioned trial, regardless of other risk subgroups, denosumab consistently and significantly increased BMD over 3 years compared to placebo. ${ }^{37}$ The subgroups included in the analysis were age ( $<70$ years or $\geq 70$ years), body mass index (BMI, $<26 \mathrm{~kg} / \mathrm{m}^{2}$ or $\geq 26 \mathrm{~kg} / \mathrm{m}^{2}$ ), prevalent vertebral fracture (yes or no), LS BMD T-score $(<-1.0$ or $\geq-1.0)$, TH BMD T-score $(<-1.0$ or $\geq-1.0)$, OTR BMD T-score $(<-1.0$ or $\geq-1.0)$, months prior ADT ( $<6$ or $\geq 6$ ), type of prior ADT ( $\mathrm{GnRh}$ agonist or bilateral orchidectomy), and baseline biochemical marker levels (CTX and TRAP-5b). Men who had a shorter period of prior ADT had a better response in LS BMD to denosumab, underscoring the importance of preventing bone loss. Further, men having the highest levels of bone resorption at baseline had the greatest response to denosumab therapy. This study demonstrated that in men treated with androgen ablation for prostate cancer, denosumab works effectively in preventing bone loss in all subgroups.

In a phase 2 trial, treatment with denosumab in patients with bone metastases decreased uNTX even after prior therapy with intravenous (IV) zoledronic acid. ${ }^{135}$ In a substudy of the aforementioned study involving the prostate cancer patients only, denosumab normalized uNTX to a greater extent than the continued administration of IV bisphosphonate. ${ }^{136}$ This study demonstrated that denosumab decreases bone resorption to a greater extent than IV bisphosphonates in prostate cancer patients.

Denosumab is an effective therapy for the preservation of bone mass and the avoidance of skeletal-related AEs during ADT in men with prostate cancer.

\section{Denosumab and treatment-induced bone loss with aromatase-inhibitor therapy}

Aromatase-inhibitor therapy for hormone-sensitive breast cancer rapidly increases bone resorption and decreases BMD. Prevention of aromatase-inhibitor-induced bone loss during treatment for breast cancer is an important concern.

A 2-year phase 3 trial of denosumab (60 mg Q6m) vs placebo in the treatment of women with breast cancer undergoing aromatase-inhibitor therapy ${ }^{137}$ showed that after a year of denosumab, LS BMD increased by $5.5 \%$ compared to the placebo group; the BMD gains were independent of duration of aromatase-inhibitor use or type, or prior tamoxifene use. Significant differences in LS BMD between groups were observed at 1 month after therapy initiation and these continued through 2 years (7.6\% at 2 years). Significant gains in BMD occurred at sites, including the OTR. After 1 month of denosumab therapy, the earliest evaluation, the levels of 


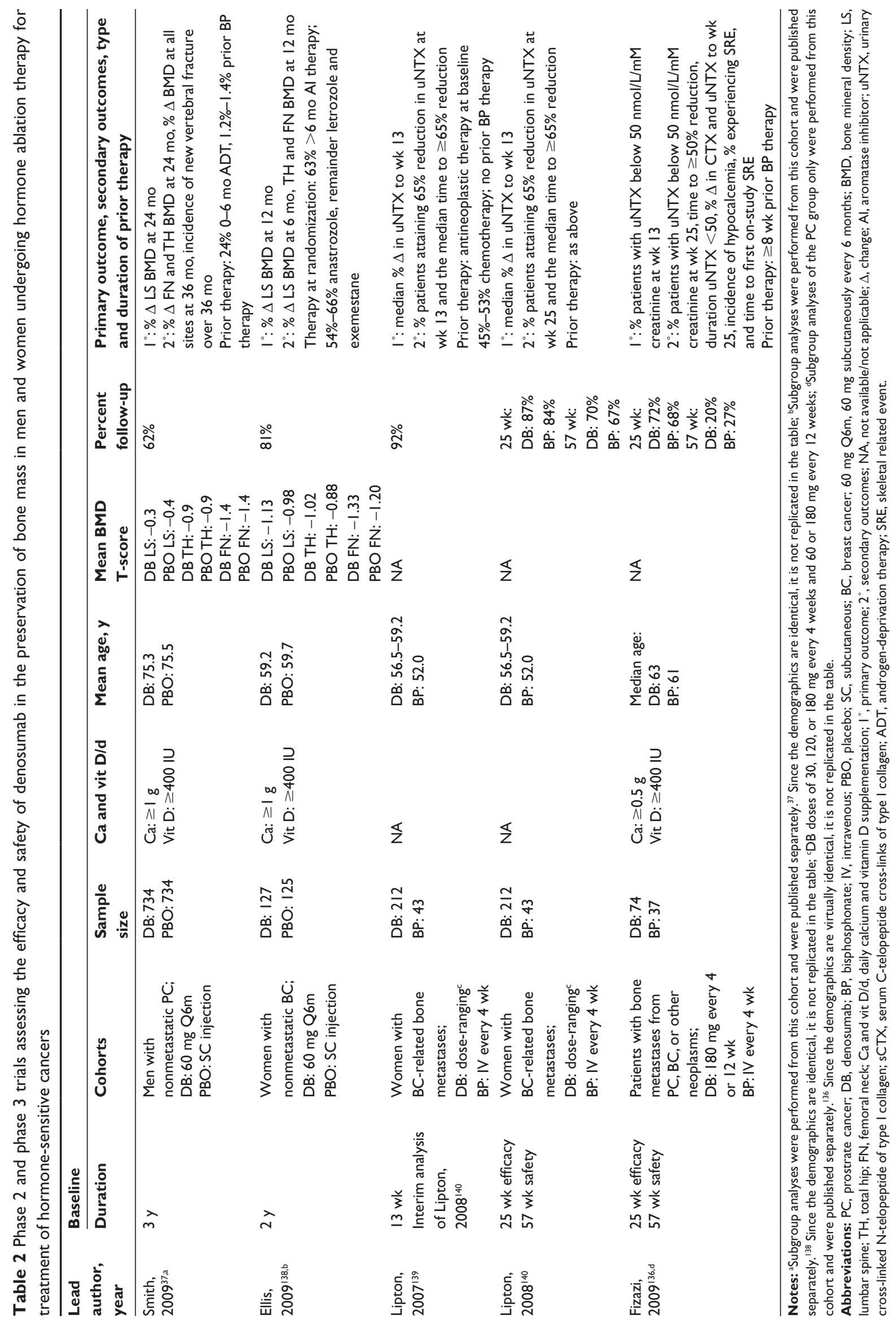


sCTX and P1NP were reduced by a median $91 \%$ and $29 \%$, respectively, and from 6 to 24 months there was $63 \%-80 \%$ and $71 \%-73 \%$ suppression, respectively.

In a subgroup analysis of this study, denosumab worked equally well and at all BMD sites for all subgroups investigated (duration and type of aromatase-inhibitor, tamoxifene use, age, time since menopause, BMI, and BMD T-score). ${ }^{138}$

Bisphosphonate-naive women with breast cancer-related bone metastases received 1 of 5 doses of denosumab (every 4 weeks at 30,120 , or $180 \mathrm{mg}$; or every 12 weeks at 60 or $180 \mathrm{mg}$ ) or denosumab with open-label IV bisphosphonate. ${ }^{139}$ After 13 weeks, there was a 73\% reduction in uNTX for the overall denosumab group and a 79\% reduction for the bisphosphonate group. In total, $74 \%$ of the denosumab patients met the target reduction in resorption suppression $(>65 \%$ reduction in UNTX), whereas only $63 \%$ of the bisphosphonate group did so. Skeletal-related AEs were experienced by $9 \%$ of the denosumab-treated patients and $16 \%$ of the bisphosphonate group. In a continuation of the aforementioned study, ${ }^{140}$ the uNTX decrease for the denosumab group was 75\% and for the bisphosphonate group $71 \%$, with $52 \%$ and $46 \%$ of the denosumab and bisphosphonate groups attaining the target suppression at 25 weeks, respectively. Total skeletal-related AEs were $12 \%$ for the denosumab-treated patients and $16 \%$ for the bisphosphonate-treated patients.

These studies demonstrated that denosumab leads to rapid reductions in bone turnover and significant increases in BMD in women undergoing aromatase-inhibitor therapy for breast cancer. Many patients on bisphosphonate therapy receiving advanced care for cancer do not attain acceptable levels of suppression of bone resorption with current bisphosphonate therapies. $^{141}$

\section{Safety and tolerability of denosumab}

Denosumab has a good safety profile, with consistent findings from phase 2 and 3 trials in postmenopausal women and from men and women receiving therapy for hormone-sensitive cancers.

The majority of clinical trials with denosumab have reported rates of AEs and serious AEs (SAEs) that are comparable to placebo or comparator groups (ie, alendronate) over 1 year, ${ }^{98,106,137} 2$ years, ${ }^{103,105,130} 3$ years, ${ }^{117}$ and 4 years. ${ }^{104}$

The best trial to evaluate AEs is the FREEDOM trial, ${ }^{117}$ with nearly 4,000 patients in each denosumab treatment group followed over 3 years. This trial will be extended to 10 years, and ongoing surveillance should alert us regarding later safety issues in adequate time. In this trial, there are no sig- nificant differences between the placebo and the denosumab groups in terms of rates of AEs or SAEs, or discontinuation due to AEs over 3 years of follow-up. Over 3 years of therapy, eczema was reported in $3.0 \%$ of denosumab subjects and $1.7 \%$ of the placebo group $(P<0.001)$. Twelve subjects $(0.3 \%)$ in the denosumab group reported SAEs of cellulitis, vs $1(<0.01 \%)$ in the placebo group $(P=0.002)$, but there was no overall difference in the rate of cellulitis between the groups (denosumab: 1.2\% vs placebo: 0.9\%).

In the 2-year DEFEND trial, ${ }^{105} \mathrm{SAEs}$ occurred in $11 \%$ of the denosumab group and $5.5 \%$ of the placebo group $(P=0.074)$. In the 4 years of data from the phase 2 trials, ${ }^{102-104}$ SAEs were experienced in $11 \%$ of the placebo group, $18 \%$ of the denosumab group, and $17 \%$ of the alendronate group. In the comparator trials with alendronate, significantly higher rates of gastrointestinal AEs (dyspepsia, nausea) were reported compared to those reported with denosumab or placebo. ${ }^{102-104}$

The higher numbers of SAEs with denosumab in the DEFEND trial were mostly due to a higher number of hospital-treated infections, with no opportunistic infections reported; all hospitalization infections recovered with standard antibiotic treatment, and no infection was considered to be a result of the study drug. In the FREEDOM trial, ${ }^{117}$ there were 4 cases of opportunistic infection in the denosumab group and 3 in the placebo group. In the 4 years of data from the phase 2 trials, ${ }^{102-104}$ a total of $3.2 \%$ of the denosumab-treated patients reported as having contracted an infection requiring hospitalization; however, none were opportunistic and all were treated successfully by standard antibiotics. The overall infection rate was similar for all groups (67\% placebo, $66 \%$ denosumab, and $70 \%$ alendronate). In the treatment of prostate cancer, SAEs related to infection were reported in $5.9 \%$ of the denosumabtreated patients and in $4.6 \%$ of the placebo-treated patients. ${ }^{130}$

Although the overall rates of AEs and SAEs are similar in denosumab and placebo groups, patients hospitalized with cellulitis, eczema, and erysipelis increased with denosumab therapy. Though these events are infrequent and easily resolved, postmarketing surveillance and the results of longer-term trials need to be monitored.

The ligand, RANKL, activates the RANK receptor and may be responsible for $\mathrm{T}$ cell growth and for dendritic cell-function. ${ }^{61,142}$ Reducing RANKL activity may lead to a greater susceptibility to infections and malignancies. ${ }^{143}$ This, however, is most likely a redundant mechanism of immune competence, and clinical trials have not demonstrated any overall increase in the risk of infection or malignancy. In the large clinical trials conducted to date, an increase in hospitalized cellulitis, but no overall increases in the rate of infections 
or cancers, has been observed. In the DEFEND prevention trial, ${ }^{105}$ there were 4 neoplasms in the denosumab group and 1 in the placebo group and in a 1-year denosumab vs placebo trial, there was no significant difference in the incidence of malignancies. ${ }^{106}$ Regardless, there is need to monitor for longterm side effects of denosumab therapy, including increases in infection and cancer rates.

Neutralizing antidenosumab antibodies would be problematic for patients undergoing long-term therapy and have been assayed on many of the denosumab clinical trials. To date, no neutralizing antidenosumab antibodies have been detected in any of the clinical trials, with up to 4 years of follow-up. ${ }^{102-106,117,128,130,137}$ In the phase 2 trial, ${ }^{102} 2$ patients who received denosumab had detectable denosumab-binding antibodies that were found to be nonneutralizing and were not detected with subsequent testing. In the DEFEND prevention $^{105}$ study, 2 subjects (1\%) in the denosumab group and 3 subjects $(2 \%)$ in the placebo group tested positive for antidenosumab antibodies, but all were nonneutralizing.

There have been no significant laboratory AEs reported with denosumab use, ${ }^{102,103,105,106}$ no changes in immune parameters, and no reports of symptomatic hypocalcemia, with up to 4 years of follow-up. ${ }^{103-106,137}$ Bone biopsies (nonpaired) taken after different lengths of exposure to denosumab show low bone turnover with no signs of osteomalacia, woven bone, or other bone metabolic pathologies. ${ }^{144}$

The infrequent occurrence of osteonecrosis of the jaw ${ }^{145}$ and atypical fractures of the proximal femoral shaft, ${ }^{146}$ which is a cause of concern, with the use of amino bisphosphonates, themselves potent suppressors of bone turnover, have led to questions regarding the possibility of occurrence of these events with denosumab. To date, there are no published data reporting a relationship between denosumab and atypical fractures. Recently, 3 papers were published that report the occurrence of osteonecrosis of the jaw in women and men receiving denosumab for the treatment of advanced cancers ${ }^{147,148}$ or severe osteoporosis. ${ }^{149}$ In a letter to the editor, a group reported composite data from 2 trials involving denosumab treatment of metastases in bisphosphonate-naive patients with advanced cancers. ${ }^{148}$ It was suggested that doses of denosumab over $120 \mathrm{mg}$ per month may be associated with an increased risk of osteonecrosis of the jaw (estimated number needed to harm, 67). A case study reported the development of osteonecrosis of the jaw in a 65-year-old woman with a significant clinical history including non-insulin-dependent diabetes, morbid obesity, below-knee amputation of one leg due to congenitally missing fibula, hypertension, congestive heart failure, and sacral cell giant cell tumor, among others, who was treated with 120-mg denosumab weekly for 3 weeks and then with $120 \mathrm{mg}$ injection monthly for 2-3 years after suffering numerous vertebral fractures. ${ }^{149}$ Lastly, a 60-yearold man was reported to have suffered osteonecrosis of the jaw after receiving denosumab for metastatic prostatic adenocarcinoma. ${ }^{147}$ After 15 months of denosumab discontinuation, there were no symptoms of osteonecrosis. Additional data are required to investigate the association between denosumab use and osteonecrosis.

\section{Interactions with other diseases and therapies}

There is no demonstrated adverse interaction of denosumab with any therapy studied. Concern has been expressed that immune dysfunction induced by biologic therapy for inflammatory arthritis (known to increase risk of infection) may further increase infection risk. Although there are no data, there is theoretical concern that interaction of denosumab with the RANKL and RANK system in immune cells may further increase infection risk. Preclinical ${ }^{150}$ and clinical data $^{98}$ support the contention that RANK or RANKL plays a redundant and nonessential role in the adult immune system, at least in most patients.

In a dose-escalation study, there were no overt safety signals and there were no clinically significant changes associated with denosumab administration on lymphocyte counts overall (CD3), T cells (CD4, CD8, CD56), or B cells (CD20).$^{98}$ Further, no meaningful differences were observed between the placebo and denosumab groups with respect to infectious events.

\section{Patient-focused perspectives of therapy with denosumab} Patient satisfaction or acceptability

Patients studied in the denosumab trials with alendronate comparison completed preference and satisfaction questionnaires after participating in 1 of 2 12-month doubledummy studies, ${ }^{106,107}$ where they had received both a weekly oral tablet and twice-yearly subcutaneous injections. ${ }^{49}$ Significantly $(P<0.001)$, more patients preferred the 6-month injections $(63 \%-65 \%)$ compared to the weekly oral tablet (19\%). Furthermore, 90\% had no problem with the subcutaneous injections, whereas $62 \%$ had no problem with the tablets. Patients preferred, were more satisfied, and less bothered with a 6-month subcutaneous injection regimen for osteoporosis as compared to a once-weekly oral tablet.

\section{Adherence}

Adherence rates for osteoporosis medications are poor, and 1-year nonadherence rates of more than $50 \%$ are 
common. ${ }^{151-153}$ Studies of osteoporosis therapies have demonstrated that, in general, those therapies that are dosed less frequently are better adhered to by patients. ${ }^{50}$

Since denosumab is administered only twice-yearly by subcutaneous injection, adherence can be easily ensured through supervision or administration by a health professional. The subcutaneous administration also avoids the potential AEs and strict dosing instructions associated with some of the oral bisphosphonates.

With adherence rates approximating those recorded in clinical trials, it is hoped that the effectiveness of denosumab in the real-world clinical setting can match the efficacy of the clinical trial setting with regards to safety and fracture risk reduction.

\section{Conclusions}

Denosumab is an antiresorptive therapy that has a unique mechanism of action and broader applicability compared to other antiresorptive drugs. Whereas bisphosphonates bind to bone and act on mature osteoclasts, denosumab does not bind to bone and acts on both immature and mature osteoclasts, inhibiting their recruitment, maturation, and activity. Denosumab's mechanism of action provides it with some unique benefits that include rapid onset of action, longer action (up to 6 months), and easy reversibility. Since denosumab does not bind to bone and become incorporated into bone, its reversibility may be particularly important. Safety concerns (osteonecrosis, atypical fracture) and efficacy concerns (bone fragility and oversuppression) may be addressed by therapy with a nonbisphosphonate medication with demonstrated rapid reversibility.

Denosumab has demonstrated antifracture efficacy at all relevant skeletal sites in a single trial. These overall fracture risk reductions have been matched only by those from zoledronic acid in higher fracture risk population (Figures 6, 7, and 8). It must be noted, however, that direct comparison of antifracture efficacy of different osteoporosis medications has not been performed in a single head-to-head study; so, conclusive statements regarding comparative efficacy is not possible. Imaging suggests a greater cortical effect than bisphosphonates and the potential for greater nonvertebral antifracture efficacy over the long term. The greater magnitude of decrease in BTMs and increase in BMD may be associated with a greater reduction in fracture risk. ${ }^{154}$

Denosumab's twice-yearly dosing may increase adherence to osteoporosis medication. This will have a significant beneficial impact on the reduction of the burden of illness of osteoporosis.

No clinically significant safety concerns have been associated with the use of denosumab therapy, but hospitalized patients with cellulitis and erysipelas need to be monitored with long-term surveillance.

The pricing of denosumab has not been established in countries where its approval is still pending. Pricing in countries where denosumab has obtained regulatory approval is competitive with existing brands of osteoporosis products.

Denosumab may provide an important addition to our armamentarium of options available for the prevention and treatment of osteoporosis and for the prevention of treatmentinduced bone loss during some prostate cancer and breast cancer therapy.

\section{Acknowledgment}

Amgen provided funding for medical writing support. Development of the manuscript was the sole responsibility of the authors without participation from Amgen.

\section{Disclosure}

Dr Kendler has received research grants, served on the speakers bureau, and/or has acted as a consultant for Amgen, Novartis, Eli Lilly, Merck, Roche, GSK, Servier, Biosante, and Pfizer. Dr Davison has received research grants, served on the speakers bureau, and/or has acted as a consultant for Amgen, Novartis, Merck Frosst, Servier, Warner Chilcott PLC and sanofi-aventis.

\section{References}

1. NIH Consensus Development Panel on Osteoporosis Prevention, Diagnosis, and Therapy. Osteoporosis prevention, diagnosis, and therapy. JAMA. 2001;285(6):785-795.

2. Adachi JD, Ioannidis G, Berger C, et al. The influence of osteoporotic fractures on health-related quality of life in community-dwelling men and women across Canada. Osteoporos Int. 2001;12(11):903-908.

3. Papaioannou A, Kennedy CC, Ioannidis G, et al. The impact of incident fractures on health-related quality of life: 5 years of data from the Canadian Multicentre Osteoporosis Study. Osteoporos Int. 2009; 20(5):703-714.

4. Ioannidis G, Papaioannou A, Hopman WM, et al. Relation between fractures and mortality: results from the Canadian Multicentre Osteoporosis Study. CMAJ. 2009;181(5):265-271.

5. Wiktorowicz ME, Goeree R, Papaioannou A, Adachi JD, Papadimitropoulos E. Economic implications of hip fracture: health service use, institutional care and cost in Canada. Osteoporos Int. 2001; 12(4):271-278.

6. Warriner AH, Curtis JR. Adherence to osteoporosis treatments: room for improvement. Curr Opin Rheumatol. 2009;21(4):356-362.

7. Kaufmann M, Jonat W, Hilfrich J, et al. Improved overall survival in postmenopausal women with early breast cancer after anastrozole initiated after treatment with tamoxifen compared with continued tamoxifen: the ARNO 95 Study. J Clin Oncol. 2007;25(19): 2664-2670.

8. Baum M, Buzdar A, Cuzick J, et al. Anastrozole alone or in combination with tamoxifen versus tamoxifen alone for adjuvant treatment of postmenopausal women with early-stage breast cancer: results of the ATAC (Arimidex, Tamoxifen Alone or in Combination) trial efficacy and safety update analyses. Cancer. 2003;98(9): $1802-1810$. 
9. Coombes RC, Hall E, Gibson LJ, et al. A randomized trial of exemestane after two to three years of tamoxifen therapy in postmenopausal women with primary breast cancer. N Engl J Med. 2004; 350(11):1081-1092.

10. Goss PE, Ingle JN, Martino S, et al. A randomized trial of letrozole in postmenopausal women after five years of tamoxifen therapy for early-stage breast cancer. $N$ Engl J Med. 2003;349(19): 1793-1802.

11. Thurlimann B, Keshaviah A, Coates AS, et al. A comparison of letrozole and tamoxifen in postmenopausal women with early breast cancer. N Engl J Med. 2005;353(26):2747-2757.

12. Eastell R, Hannon R. Long-term effects of aromatase inhibitors on bone. J Steroid Biochem Mol Biol. 2005;95(1-5):151-154.

13. Gnant MF, Mlineritsch B, Luschin-Ebengreuth G, et al. Zoledronic acid prevents cancer treatment-induced bone loss in premenopausal women receiving adjuvant endocrine therapy for hormoneresponsive breast cancer: a report from the Austrian Breast and Colorectal Cancer Study Group. J Clin Oncol. 2007;25(7): $820-828$.

14. Lonning PE, Geisler J, Krag LE, et al. Effects of exemestane administered for 2 years versus placebo on bone mineral density, bone biomarkers, and plasma lipids in patients with surgically resected early breast cancer. J Clin Oncol. 2005;23(22):5126-5137.

15. Coombes RC, Kilburn LS, Snowdon CF, et al. Survival and safety of exemestane versus tamoxifen after 2-3 years' tamoxifen treatment (Intergroup Exemestane Study): a randomised controlled trial. Lancet. 2007;369(9561):559-570.

16. Howell A, Cuzick J, Baum M, et al. Results of the ATAC (Arimidex, Tamoxifen, Alone or in Combination) trial after completion of 5 years' adjuvant treatment for breast cancer. Lancet. 2005;365(9453):60-62.

17. Goss PE, Ingle JN, Martino S, et al. Randomized trial of letrozole following tamoxifen as extended adjuvant therapy in receptor-positive breast cancer: updated findings from NCIC CTG MA.17. J Natl Cancer Inst. 2005;97(17):1262-1271.

18. Jakesz R, Jonat W, Gnant M, et al. Switching of postmenopausal women with endocrine-responsive early breast cancer to anastrozole after 2 years' adjuvant tamoxifen: combined results of ABCSG trial 8 and ARNO 95 trial. Lancet. 2005;366(9484):455-462.

19. Thurlimann B, Keshaviah A, Coates AS, et al. A comparison of letrozole and tamoxifen in postmenopausal women with early breast cancer. N Engl J Med. 2005;353(26):2747-2757.

20. Heidenreich A, Aus G, Bolla M, et al. EAU guidelines on prostate cancer. Eur Urol. 2008;53(1):68-80.

21. Loblaw DA, Virgo KS, Nam R, et al. Initial hormonal management of androgen-sensitive metastatic, recurrent, or progressive prostate cancer: 2006 update of an American Society of Clinical Oncology practice guideline. J Clin Oncol. 2007;25(12):1596-1605.

22. Sharifi N, Gulley JL, Dahut WL. Androgen deprivation therapy for prostate cancer. JAMA. 2005;294(2):238-244.

23. Shahinian VB, Kuo YF, Freeman JL, Goodwin JS. Risk of fracture after androgen deprivation for prostate cancer. $N$ Engl J Med. 2005; 352(2):154-164.

24. Smith MR, Lee WC, Brandman J, Wang Q, Botteman M, Pashos CL. Gonadotropin-releasing hormone agonists and fracture risk: a claimsbased cohort study of men with nonmetastatic prostate cancer. $J$ Clin Oncol. 2005;23(31):7897-7903.

25. Higano CS. Androgen-deprivation-therapy-induced fractures in men with nonmetastatic prostate cancer: what do we really know? Nat Clin Pract Urol. 2008;5(1):24-34.

26. Michaelson MD, Marujo RM, Smith MR. Contribution of androgen deprivation therapy to elevated osteoclast activity in men with metastatic prostate cancer. Clin Cancer Res. 2004;10(8): 2705-2708.

27. Smith MR, McGovern FJ, Zietman AL, et al. Pamidronate to prevent bone loss during androgen-deprivation therapy for prostate cancer. N Engl J Med. 2001;345(13):948-955.
28. Brown JE, Cook RJ, Major P, et al. Bone turnover markers as predictors of skeletal complications in prostate cancer, lung cancer, and other solid tumors. J Natl Cancer Inst. 2005;97(1):59-69.

29. Clarke NW, McClure J, George NJ. Morphometric evidence for bone resorption and replacement in prostate cancer. Br J Urol. 1991;68(1): 74-80.

30. Brown JE, Thomson CS, Ellis SP, Gutcher SA, Purohit OP, Coleman RE. Bone resorption predicts for skeletal complications in metastatic bone disease. Br J Cancer. 2003;89(11):2031-2037.

31. Greenspan SL, Coates P, Sereika SM, Nelson JB, Trump DL, Resnick NM. Bone loss after initiation of androgen deprivation therapy in patients with prostate cancer. $J$ Clin Endocrinol Metab. 2005;90(12):6410-6417.

32. Krupski TL, Smith MR, Lee WC, et al. Natural history of bone complications in men with prostate carcinoma initiating androgen deprivation therapy. Cancer. 2004;101(3):541-549.

33. Lee H, McGovern K, Finkelstein JS, Smith MR. Changes in bone mineral density and body composition during initial and long-term gonadotropin-releasing hormone agonist treatment for prostate carcinoma. Cancer. 2005;104(8):1633-1637.

34. Oefelein MG, Ricchiuti V, Conrad W, Resnick MI. Skeletal fractures negatively correlate with overall survival in men with prostate cancer. J Urol. 2002;168(3):1005-1007.

35. Brufsky A, Harker WG, Beck JT, et al. Zoledronic acid inhibits adjuvant letrozole-induced bone loss in postmenopausal women with early breast cancer. J Clin Oncol. 2007;25(7):829-836.

36. Coleman RE, Banks LM, Girgis SI, et al. Skeletal effects of exemestane on bone-mineral density, bone biomarkers, and fracture incidence in postmenopausal women with early breast cancer participating in the Intergroup Exemestane Study (IES): a randomised controlled study. Lancet Oncol. 2007;8(2):119-127.

37. Smith MR, Saad F, Egerdie B, et al. Effects of denosumab on bone mineral density in men receiving androgen deprivation therapy for prostate cancer. J Urol. 2009;182(6):2670-2675.

38. Ellis GK, Bone HG, Chlebowski R, et al. Randomized trial of denosumab in patients receiving adjuvant aromatase inhibitors for nonmetastatic breast cancer. J Clin Oncol. 2008;26(30):4875-4882.

39. Consensus development conference: diagnosis, prophylaxis, and treatment of osteoporosis. Am J Med. 1993;94(6):646-650.

40. Siris ES, Chen YT, Abbott TA, et al. Bone mineral density thresholds for pharmacological intervention to prevent fractures. Arch Intern Med. 2004;164(10):1108-1112.

41. Cranney A, Jamal SA, Tsang JF, Josse RG, Leslie WD. Low bone mineral density and fracture burden in postmenopausal women. CMAJ. 2007;177(6):575-580.

42. Nevitt MC, Cummings SR, Stone KL, et al. Risk factors for a firstincident radiographic vertebral fracture in women $>$ or $=65$ years of age: the study of osteoporotic fractures. J Bone Miner Res. 2005;20(1):131-140.

43. Kanis JA, Johnell O, de Laet C, et al. A meta-analysis of previous fracture and subsequent fracture risk. Bone. 2004;35(2): 375-382.

44. Brown JP, Josse RG; Scientific Advisory Council of the Osteoporosis Society of Canada. 2002 clinical practice guidelines for the diagnosis and management of osteoporosis in Canada. CMAJ. 2002;167 10 Suppl: S1-S34.

45. Kanis JA, McCloskey EV, Johansson H, Oden A, Strom O, Borgstrom F. Development and use of FRAX in osteoporosis. Osteoporos Int. 2010;21 Suppl 2:S407-S413.

46. Simon JA, Lewiecki EM, Smith ME, Petruschke RA, Wang L, Palmisano JJ. Patient preference for once-weekly alendronate $70 \mathrm{mg}$ versus once-daily alendronate $10 \mathrm{mg}$ : a multicenter, randomized, open-label, crossover study. Clin Ther. 2002;24(11): 1871-1886.

47. Reginster JY, Rabenda V, Neuprez A. Adherence, patient preference and dosing frequency: understanding the relationship. Bone. 2006;38 (4 Suppl 1):S2-S6. 
48. de Bekker-Grob EW, Essink-Bot ML, Meerding WJ, Pols HA, Koes BW, Steyerberg EW. Patients' preferences for osteoporosis drug treatment: a discrete choice experiment. Osteoporos Int. 2008;19(7): 1029-1037.

49. Kendler DL, Bessette L, Hill CD, et al. Preference and satisfaction with a 6-month subcutaneous injection versus a weekly tablet for treatment of low bone mass. Osteoporos Int. 2010;21(5):837-846.

50. Cramer JA, Gold DT, Silverman SL, Lewiecki EM. A systematic review of persistence and compliance with bisphosphonates for osteoporosis Osteoporos Int. 2007;18(8):1023-1031.

51. Neumann E, Gay S, Muller-Ladner U. The RANK/RANKL/osteoprotegerin system in rheumatoid arthritis: new insights from animal models. Arthritis Rheum. 2005;52(10):2960-2967.

52. Lacey DL, Timms E, Tan HL, et al. Osteoprotegerin ligand is a cytokine that regulates osteoclast differentiation and activation. Cell. 1998;93(2):165-176.

53. Burgess TL, Qian Y, Kaufman S, et al. The ligand for osteoprotegerin (OPGL) directly activates mature osteoclasts. J Cell Biol. 1999;145(3): $527-538$.

54. Lacey DL, Tan HL, Lu J, et al. Osteoprotegerin ligand modulates murine osteoclast survival in vitro and in vivo. Am J Pathol. 2000; 157(2):435-448

55. Yasuda H, Shima N, Nakagawa N, et al. Osteoclast differentiation factor is a ligand for osteoprotegerin/osteoclastogenesis-inhibitory factor and is identical to TRANCE/RANKL. Proc Natl Acad Sci U S A. 1998; 95(7):3597-3602.

56. Fuller K, Wong B, Fox S, Choi Y, Chambers TJ. TRANCE is necessary and sufficient for osteoblast-mediated activation of bone resorption in osteoclasts. J Exp Med. 1998;188(5):997-1001.

57. Li J, Sarosi I, Yan XQ, et al. RANK is the intrinsic hematopoietic cell surface receptor that controls osteoclastogenesis and regulation of bone mass and calcium metabolism. Proc Natl Acad Sci U S A. 2000;97(4): 1566-1571.

58. Nakagawa N, Kinosaki M, Yamaguchi K, et al. RANK is the essential signaling receptor for osteoclast differentiation factor in osteoclastogenesis. Biochem Biophys Res Commun. 1998;253(2):395-400.

59. Hsu H, Lacey DL, Dunstan CR, et al. Tumor necrosis factor receptor family member RANK mediates osteoclast differentiation and activation induced by osteoprotegerin ligand. Proc Natl Acad Sci U S A. 1999; 96(7):3540-3545.

60. Gori F, Hofbauer LC, Dunstan CR, Spelsberg TC, Khosla S, Riggs BL. The expression of osteoprotegerin and RANK ligand and the support of osteoclast formation by stromal-osteoblast lineage cells is developmentally regulated. Endocrinology. 2000;141(12): 4768-4776.

61. Kong YY, Yoshida H, Sarosi I, et al. OPGL is a key regulator of osteoclastogenesis, lymphocyte development and lymph-node organogenesis. Nature. 1999;397(6717):315-323.

62. Simonet WS, Lacey DL, Dunstan CR, et al. Osteoprotegerin: a novel secreted protein involved in the regulation of bone density. Cell. 1997; 89(2):309-319.

63. Bolon B, Shalhoub V, Kostenuik PJ, et al. Osteoprotegerin, an endogenous antiosteoclast factor for protecting bone in rheumatoid arthritis. Arthritis Rheum. 2002;46(12):3121-3135.

64. Campagnuolo G, Bolon B, Feige U. Kinetics of bone protection by recombinant osteoprotegerin therapy in Lewis rats with adjuvant arthritis. Arthritis Rheum. 2002;46(7):1926-1936.

65. Kostenuik PJ, Bolon B, Morony S, et al. Gene therapy with human recombinant osteoprotegerin reverses established osteopenia in ovariectomized mice. Bone. 2004;34(4):656-664.

66. Mochizuki S, Fujise N, Higashio K, Tsuda E. Osteoclastogenesis inhibitory factor/osteoprotegerin ameliorates the decrease in both bone mineral density and bone strength in immobilized rats. J Bone Miner Metab. 2002;20(1):14-20.

67. Capparelli C, Morony S, Warmington K, et al. Sustained antiresorptive effects after a single treatment with human recombinant osteoprotegerin (OPG): a pharmacodynamic and pharmacokinetic analysis in rats. J Bone Miner Res. 2003;18(5):852-858.
68. Ross AB, Bateman TA, Kostenuik PJ, et al. The effects of osteoprotegerin on the mechanical properties of rat bone. JMater Sci Mater Med. 2001;12(7):583-588.

69. Bekker PJ, Holloway D, Nakanishi A, Arrighi M, Leese PT, Dunstan CR. The effect of a single dose of osteoprotegerin in postmenopausal women. J Bone Miner Res. 2001;16(2):348-360.

70. Bucay N, Sarosi I, Dunstan CR, et al. Osteoprotegerin-deficient mice develop early onset osteoporosis and arterial calcification. Genes Dev. 1998;12(9):1260-1268.

71. Kostenuik PJ, Capparelli C, Morony S, et al. OPG and PTH-(1-34) have additive effects on bone density and mechanical strength in osteopenic ovariectomized rats. Endocrinology. 2001;142(10):4295-4304.

72. Hughes AE, Ralston SH, Marken J, et al. Mutations in TNFRSF11A, affecting the signal peptide of RANK, cause familial expansile osteolysis. Nat Genet. 2000;24(1):45-48.

73. Kong YY, Feige U, Sarosi I, et al. Activated T cells regulate bone loss and joint destruction in adjuvant arthritis through osteoprotegerin ligand. Nature. 1999;402(6759):304-309.

74. Romas E, Sims NA, Hards DK, et al. Osteoprotegerin reduces osteoclast numbers and prevents bone erosion in collagen-induced arthritis. Am J Pathol. 2002;161(4):1419-1427.

75. Haynes DR, Crotti TN, Potter AE, et al. The osteoclastogenic molecules RANKL and RANK are associated with periprosthetic osteolysis. J Bone Joint Surg Br. 2001;83(6):902-911.

76. Crotti TN, Smith MD, Weedon H, et al. Receptor activator NF-kappaB ligand (RANKL) expression in synovial tissue from patients with rheumatoid arthritis, spondyloarthropathy, osteoarthritis, and from normal patients: semiquantitative and quantitative analysis. Ann Rheum Dis. 2002;61(12):1047-1054.

77. Gravallese EM, Manning C, Tsay A, et al. Synovial tissue in rheumatoid arthritis is a source of osteoclast differentiation factor. Arthritis Rheum. 2000;43(2):250-258.

78. Ritchlin CT, Haas-Smith SA, Li P, Hicks DG, Schwarz EM. Mechanisms of TNF-alpha- and RANKL-mediated osteoclastogenesis and bone resorption in psoriatic arthritis. J Clin Invest. 2003;111(6):821-831.

79. Zhang J, Dai J, Qi Y, et al. Osteoprotegerin inhibits prostate cancerinduced osteoclastogenesis and prevents prostate tumor growth in the bone. J Clin Invest. 2001;107(10):1235-1244.

80. Brown JM, Corey E, Lee ZD, et al. Osteoprotegerin and rank ligand expression in prostate cancer. Urology. 2001;57(4):611-616.

81. Body JJ, Greipp P, Coleman RE, et al. A phase I study of AMGN-0007, a recombinant osteoprotegerin construct, in patients with multiple myeloma or breast carcinoma related bone metastases. Cancer. 2003; 97 Suppl 3:S887-S892.

82. Croucher PI, Shipman CM, Lippitt J, et al. Osteoprotegerin inhibits the development of osteolytic bone disease in multiple myeloma. Blood. 2001;98(13):3534-3540.

83. Sezer O, Heider U, Zavrski I, Kuhne CA, Hofbauer LC. RANK ligand and osteoprotegerin in myeloma bone disease. Blood. 2003;101(6): 2094-2098.

84. Roux S, Meignin V, Quillard J, et al. RANK (receptor activator of nuclear factor-kappaB) and RANKL expression in multiple myeloma. Br J Haematol. 2002;117(1):86-92.

85. Giuliani N, Bataille R, Mancini C, Lazzaretti M, Barille S. Myeloma cells induce imbalance in the osteoprotegerin/osteoprotegerin ligand system in the human bone marrow environment. Blood. 2001;98(13): 3527-3533.

86. Kitazawa S, Kitazawa R. RANK ligand is a prerequisite for cancerassociated osteolytic lesions. J Pathol. 2002;198(2):228-236.

87. Morony S, Capparelli C, Lee R, et al. A chimeric form of osteoprotegerin inhibits hypercalcemia and bone resorption induced by IL-1 beta, TNFalpha, PTH, PTHrP, and 1, 25(OH)2D3. J Bone Miner Res. 1999;14(9): 1478-1485.

88. Mancino AT, Klimberg VS, Yamamoto M, Manolagas SC, Abe E. Breast cancer increases osteoclastogenesis by secreting M-CSF and upregulating RANKL in stromal cells. J Surg Res. 2001;100(1):18-24. 
89. Thomas RJ, Guise TA, Yin JJ, et al. Breast cancer cells interact with osteoblasts to support osteoclast formation. Endocrinology. 1999; 140(10):4451-4458.

90. Honore P, Luger NM, Sabino MA, et al. Osteoprotegerin blocks bone cancer-induced skeletal destruction, skeletal pain and painrelated neurochemical reorganization of the spinal cord. Nat Med. 2000;6(5):521-528.

91. Mantyh PW, Clohisy DR, Koltzenburg M, Hunt SP. Molecular mechanisms of cancer pain. Nat Rev Cancer. 2002;2(3):201-209.

92. Clohisy DR, Ramnaraine ML, Scully S, et al. Osteoprotegerin inhibits tumor-induced osteoclastogenesis and bone tumor growth in osteopetrotic mice. J Orthop Res. 2000;18(6):967-976.

93. Luger NM, Honore P, Sabino MA, et al. Osteoprotegerin diminishes advanced bone cancer pain. Cancer Res. 2001;61(10):4038-4047.

94. Atkins GJ, Bouralexis S, Haynes DR, et al. Osteoprotegerin inhibits osteoclast formation and bone resorbing activity in giant cell tumors of bone. Bone. 2001;28(4):370-377.

95. Tsuda E, Goto M, Mochizuki S, et al. Isolation of a novel cytokine from human fibroblasts that specifically inhibits osteoclastogenesis. Biochem Biophys Res Commun. 1997;234(1):137-142.

96. O’Brien EA, Williams JH, Marshall MJ. Osteoprotegerin is produced when prostaglandin synthesis is inhibited causing osteoclasts to detach from the surface of mouse parietal bone and attach to the endocranial membrane. Bone. 2001;28(2):208-214.

97. O’Brien EA, Williams JH, Marshall MJ. Osteoprotegerin ligand regulates osteoclast adherence to the bone surface in mouse calvaria. Biochem Biophys Res Commun. 2000;274(2):281-290.

98. Bekker PJ, Holloway DL, Rasmussen AS, et al. A single-dose placebocontrolled study of AMG 162, a fully human monoclonal antibody to RANKL, in postmenopausal women. J Bone Miner Res. 2004;19(7): 1059-1066.

99. Srivastava S, Toraldo G, Weitzmann MN, Cenci S, Ross FP, Pacifici R. Estrogen decreases osteoclast formation by down-regulating receptor activator of NF-kappa B ligand (RANKL)-induced JNK activation. J Biol Chem. 2001;276(12):8836-8840.

100. Hofbauer LC, Kuhne CA, Viereck V. The OPG/RANKL/RANK system in metabolic bone diseases. J Musculoskelet Neuronal Interact. 2004;4(3):268-275.

101. Berger C, Langsetmo L, Joseph L, et al. Change in bone mineral density as a function of age in women and men and association with the use of antiresorptive agents. CMAJ. 2008;178(13):1660-1668.

102. McClung MR, Lewiecki EM, Cohen SB, et al. Denosumab in postmenopausal women with low bone mineral density. $N$ Engl J Med. 2006; 354(8):821-831.

103. Lewiecki EM, Miller PD, McClung MR, et al. Two-year treatment with denosumab (AMG 162) in a randomized phase 2 study of postmenopausal women with low BMD. J Bone Miner Res. 2007;22(12):1832-1841.

104. Miller PD, Bolognese MA, Lewiecki EM, et al. Effect of denosumab on bone density and turnover in postmenopausal women with low bone mass after long-term continued, discontinued, and restarting of therapy: a randomized blinded phase 2 clinical trial. Bone. 2008; 43(2):222-229.

105. Bone HG, Bolognese MA, Yuen CK, et al. Effects of denosumab on bone mineral density and bone turnover in postmenopausal women. J Clin Endocrinol Metab. 2008;93(6):2149-2157.

106. Brown JP, Prince RL, Deal C, et al. Comparison of the effect of denosumab and alendronate on BMD and biochemical markers of bone turnover in postmenopausal women with low bone mass: a randomized, blinded, phase 3 trial. J Bone Miner Res. 2009;24(1): 153-161.

107. Kendler DL, Roux C, Benhamou CL, et al. Effects of denosumab on bone mineral density and bone turnover in postmenopausal women transitioning from alendronate therapy. J Bone Miner Res. 2010;25(1): 72-81.

108. Tonino RP, Meunier PJ, Emkey R, et al; Phase III Osteoporosis Treatment Study Group. Skeletal benefits of alendronate: 7-year treatment of postmenopausal osteoporotic women. J Clin Endocrinol Metab. 2000;85(9):3109-3115.
109. Schnitzer T, Bone HG, Crepaldi G, et al; Alendronate Once-Weekly Study Group. Therapeutic equivalence of alendronate $70 \mathrm{mg}$ onceweekly and alendronate $10 \mathrm{mg}$ daily in the treatment of osteoporosis. Aging (Milano). 2000;12(1):1-12.

110. Fogelman I, Ribot C, Smith R, Ethgen D, Sod E, Reginster JY; BMD-MN Study Group. Risedronate reverses bone loss in postmenopausal women with low bone mass: results from a multinational, double-blind, placebo-controlled trial. J Clin Endocrinol Metab. 2000; 85(5):1895-1900.

111. Brown JP, Kendler DL, McClung MR, et al. The efficacy and tolerability of risedronate once a week for the treatment of postmenopausal osteoporosis. 2002;71(2):103-111.

112. Reid IR, Brown JP, Burckhardt $\mathrm{P}$, et al. Intravenous zoledronic acid in postmenopausal women with low bone mineral density. $N$ Engl J Med. 2002;346(9):653-661.

113. Johnston CC Jr, Bjarnason NH, Cohen FJ, et al. Long-term effects of raloxifene on bone mineral density, bone turnover, and serum lipid levels in early postmenopausal women: three-year data from 2 doubleblind, randomized, placebo-controlled trials. Arch Intern Med. 2000; 160(22):3444-3450.

114. Sebba AI, Bonnick SL, Kagan R, et al. Response to therapy with once-weekly alendronate $70 \mathrm{mg}$ compared to once-weekly risedronate $35 \mathrm{mg}$ in the treatment of postmenopausal osteoporosis. Curr Med Res Opin. 2004;20(12):2031-2041.

115. Miller PD, Epstein S, Sedarati F, Reginster JY. Once-monthly oral ibandronate compared with weekly oral alendronate in postmenopausal osteoporosis: results from the head-to-head MOTION study. Curr Med Res Opin. 2008;24(1):207-213.

116. Rosen CJ, Hochberg MC, Bonnick SL, et al. Treatment with onceweekly alendronate $70 \mathrm{mg}$ compared with once-weekly risedronate $35 \mathrm{mg}$ in women with postmenopausal osteoporosis: a randomized double-blind study. J Bone Miner Res. 2005;20(1):141-151.

117. Cummings SR, San MJ, McClung MR, et al. Denosumab for prevention of fractures in postmenopausal women with osteoporosis. $\mathrm{N} \mathrm{Engl}$ J Med. 2009;361(8):756-765.

118. Black DM, Cummings SR, Karpf DB, et al; Fracture Intervention Trial Research Group. Randomised trial of effect of alendronate on risk of fracture in women with existing vertebral fractures. Lancet. 1996;348(9041):1535-1541.

119. Black DM, Delmas PD, Eastell R, et al. Once-yearly zoledronic acid for treatment of postmenopausal osteoporosis. N Engl J Med. 2007; 356(18):1809-1822.

120. Wells G, Cranney A, Peterson J, et al. Risedronate for the primary and secondary prevention of osteoporotic fractures in postmenopausal women. Cochrane Database Syst Rev. 2008;(1):CD004523.

121. Cummings SR, Black DM, Thompson DE, et al. Effect of alendronate on risk of fracture in women with low bone density but without vertebral fractures: results from the Fracture Intervention Trial. JAMA. 1998;280(24):2077-2082.

122. Chesnut III CH, Skag A, Christiansen C, et al. Effects of oral ibandronate administered daily or intermittently on fracture risk in postmenopausal osteoporosis. J Bone Miner Res. 2004;19(8):1241-1249.

123. Wells GA, Cranney A, Peterson J, et al. Etidronate for the primary and secondary prevention of osteoporotic fractures in postmenopausal women. Cochrane Database Syst Rev. 2008;(1):CD003376.

124. McClung MR, Geusens P, Miller PD, et al. Hip Intervention Program Study Group. Effect of risedronate on the risk of hip fracture in elderly women. N Engl J Med. 2001;344(5):333-340.

125. Harris ST, Watts NB, Genant HK, et al. Vertebral Efficacy With Risedronate Therapy (VERT) Study Group. Effects of risedronate treatment on vertebral and nonvertebral fractures in women with postmenopausal osteoporosis: a randomized controlled trial. JAMA. 1999;282(14):1344-1352.

126. Reginster J, Minne HW, Sorensen OH, et al. Vertebral Efficacy with Risedronate Therapy (VERT) Study Group. Randomized trial of the effects of risedronate on vertebral fractures in women with established postmenopausal osteoporosis. Osteoporos Int. 2000;11(1):83-91. 
127. Neer RM, Arnaud CD, Zanchetta JR, et al. Effect of parathyroid hormone (1-34) on fractures and bone mineral density in postmenopausal women with osteoporosis. N Engl J Med. 2001;344(19):1434-1441.

128. Seeman E, Delmas PD, Hanley DA, et al. Microarchitectural deterioration of cortical and trabecular bone: differing effects of denosumab and alendronate. J Bone Miner Res. Epub 2010 Mar 10.

129. Beck TJ, Lewiecki EM, Miller PD, et al. Effects of denosumab on the geometry of the proximal femur in postmenopausal women in comparison with alendronate. J Clin Densitom. 2008;11(3):351-359.

130. Smith MR, Egerdie B, Hernandez TN, et al. Denosumab in men receiving androgen-deprivation therapy for prostate cancer. $N$ Engl J Med. 2009;361(8):745-755.

131. Orwoll E, Ettinger M, Weiss S, et al. Alendronate for the treatment of osteoporosis in men. N Engl J Med. 2000;343(9):604-610.

132. Ringe JD, Faber H, Farahmand P, Dorst A. Efficacy of risedronate in men with primary and secondary osteoporosis: results of a 1-year study. Rheumatol Int. 2006;26(5):427-431.

133. Kaufman JM, Orwoll E, Goemaere S, et al. Teriparatide effects on vertebral fractures and bone mineral density in men with osteoporosis: treatment and discontinuation of therapy. Osteoporos Int. 2005;16(5):510-516.

134. Orwoll ES, Scheele WH, Paul S, et al. The effect of teriparatide [human parathyroid hormone (1-34)] therapy on bone density in men with osteoporosis. J Bone Miner Res. 2003;18(1):9-17.

135. Fizazi K, Lipton A, Mariette X, et al. Randomized phase II trial of denosumab in patients with bone metastases from prostate cancer, breast cancer, or other neoplasms after intravenous bisphosphonates. J Clin Oncol. 2009;27(10):1564-1571.

136. Fizazi K, Bosserman L, Gao G, Skacel T, Markus R. Denosumab treatment of prostate cancer with bone metastases and increased urine $\mathrm{N}$-telopeptide levels after therapy with intravenous bisphosphonates: results of a randomized phase II trial. J Urol. 2009;182(2):509-515.

137. Ellis GK, Bone HG, Chlebowski R, et al. Randomized trial of denosumab in patients receiving adjuvant aromatase inhibitors for nonmetastatic breast cancer. J Clin Oncol. 2008;26(30):4875-4882.

138. Ellis GK, Bone HG, Chlebowski R, et al. Effect of denosumab on bone mineral density in women receiving adjuvant aromatase inhibitors for non-metastatic breast cancer: subgroup analyses of a phase 3 study. Breast Cancer Res Treat. 2009;118(1):81-87.

139. Lipton A, Steger GG, Figueroa J, et al. Randomized active-controlled phase II study of denosumab efficacy and safety in patients with breast cancer-related bone metastases. J Clin Oncol. 2007;25(28): 4431-4437.

140. Lipton A, Steger GG, Figueroa J, et al. Extended efficacy and safety of denosumab in breast cancer patients with bone metastases not receiving prior bisphosphonate therapy. Clin Cancer Res. 2008;14(20):6690-6696.
141. Coleman RE, Major P, Lipton A, et al. Predictive value of bone resorption and formation markers in cancer patients with bone metastases receiving the bisphosphonate zoledronic acid. J Clin Oncol. 2005; 23(22):4925-4935.

142. Wong BR, Josien R, Lee SY, et al. TRANCE (tumor necrosis factor [TNF]-related activation-induced cytokine), a new TNF family member predominantly expressed in T cells, is a dendritic cell-specific survival factor. J Exp Med. 1997;186(12):2075-2080.

143. Schwartzman J, Yazici Y. Denosumab in postmenopausal women with low bone mineral density. N Engl J Med. 2006;354(22):2390-2391.

144. Reid IR, Benhamou CL, Bolognese MA, et al. Effects of denosumab on bone histology and histomorphometry: the FREEDOM and STAND studies. J Bone Miner Res. 2009;24 Suppl 1:S566.

145. Silverman SL, Landesberg R. Osteonecrosis of the jaw and the role of bisphosphonates: a critical review. Am J Med. 2009;122 Suppl 2 : S33-S45.

146. Giusti A, Hamdy NA, Papapoulos SE. Atypical fractures of the femur and bisphosphonate therapy A systematic review of case/case series studies. Bone. 2010;47(2):169-180.

147. Taylor KH, Middlefell LS, Mizen KD. Osteonecrosis of the jaws induced by anti-RANK ligand therapy. Br J Oral Maxillofac Surg 2010;48(3):221-223.

148. Kyrgidis A, Toulis KA. Denosumab-related osteonecrosis of the jaws Osteoporos Int. Epub 2010 Mar 20.

149. Aghaloo TL, Felsenfeld AL, Tetradis S. Osteonecrosis of the jaw in a patient on Denosumab. J Oral Maxillofac Surg. 2010;68(5): 959-963.

150. Stolina M, Kostenuik PJ, Dougall WC, Fitzpatrick LA, Zack DJ. RANKL inhibition: from mice to men (and women). Adv Exp Med Biol. 2007;602:143-150.

151. Berecki-Gisolf J, Hockey R, Dobson A. Adherence to bisphosphonate treatment by elderly women. Menopause. 2008;15(5):984-990.

152. Cotte FE, Mercier F, de PG. Relationship between compliance and persistence with osteoporosis medications and fracture risk in primary health care in France: a retrospective case-control analysis. Clin Ther. 2008;30(12):2410-2422.

153. Rabenda V, Mertens R, Fabri V, et al. Adherence to bisphosphonates therapy and hip fracture risk in osteoporotic women. Osteoporos Int. 2008;19(6):811-818.

154. Bouxsein ML, Delmas PD. Considerations for development of surrogate endpoints for antifracture efficacy of new treatments in osteoporosis: a perspective. J Bone Miner Res. 2008;23(8):1155-1167.
Orthopedic Research and Reviews

\section{Publish your work in this journal}

Orthopedic Research and Reviews is an international, peer-reviewed, open access journal that focusing on the patho-physiology of the musculoskeletal system, trauma, surgery and other corrective interventions to restore mobility and function. Advances in new technologies, materials, techniques and pharmacological agents are particularly welcome. The journal welcomes

\section{Dovepress}

original research, clinical studies, reviews \& evaluations, expert opinion and commentary, case reports and extended reports. The manuscript management system is completely online and includes a very quick and fair peer-review system, which is all easy to use. Visit http://www.dovepress. com/testimonials.php to read real quotes from published authors. 